\title{
Oxidative radical ring-opening/cyclization of cyclopropane derivatives
}

\author{
Yu Liu*, Qiao-Lin Wang, Zan Chen, Cong-Shan Zhou, Bi-Quan Xiong, Pan-Liang Zhang, \\ Chang-An Yang and Quan Zhou*
}

\author{
Review \\ Address: \\ Department of Chemistry and Chemical Engineering, Hunan Institute \\ of Science and Technology, Yueyang 414006, P. R. China \\ Email: \\ Yu Liu * lyxtmj_613@163.com; Quan Zhou* - mmzhq1985@126.com \\ * Corresponding author \\ Keywords: \\ cyclopropane derivatives; free radicals; ring-opening/cyclization
}

\author{
Beilstein J. Org. Chem. 2019, 15, 256-278. \\ doi:10.3762/bjoc. 15.23 \\ Received: 28 September 2018 \\ Accepted: 04 January 2019 \\ Published: 28 January 2019 \\ This article is part of the thematic issue "Cyclopropanes and \\ cyclopropenes: synthesis and applications". \\ Guest Editor: M. Tortosa
}

(C) 2019 Liu et al.; licensee Beilstein-Institut.

License and terms: see end of document.

\begin{abstract}
The ring-opening/cyclization of cyclopropane derivatives has drawn great attention in the past several decades. In this review, recent efforts in the development of oxidative radical ring-opening/cyclization of cyclopropane derivatives, including methylenecyclopropanes, cyclopropyl olefins and cyclopropanols, are described. We hope this review will be of sufficient interest for the scientific community to further advance the application of oxidative radical strategies in the ring-opening/cyclization of cyclopropane derivatives.
\end{abstract}

\section{Introduction}

Cyclopropane is a cycloalkane molecule with the molecular formula $\mathrm{C}_{3} \mathrm{H}_{6}$, consisting of three carbon atoms linked to each other to form a ring, with each carbon atom bearing two hydrogen atoms resulting in $D_{3 h}$ molecular symmetry. The small size of the ring creates substantial ring strain in the structure. The cyclopropane skeleton easily can take part in ring-opening reactions under certain conditions. Cyclopropane derivatives, with their three-membered carbocyclic frameworks, have spurred considerable attention especially in the domain of organic and pharmaceutical synthesis because of their highly strained threemembered carbocyclic skeletons and their easy availability
[1-16]. The cyclopropane derivatives, especially methylenecyclopropanes [17-21], cyclopropyl olefins [22] and cyclopropanols $[23,24]$ undergo ring-opening/cyclization reactions to provide a huge number of fascinating compounds with different functional groups [25-31]. However, most recently reported methods usually proceed via a radical pathway. As shown in Scheme 1 path I, the cyclopropyl-substituted carbon radical $\mathbf{D}$ is formed by the addition of radical $\mathbf{R}$ to the $\mathrm{C}-\mathrm{C}$ double bond in methylenecyclopropanes (compounds A). The cyclopropylsubstituted carbon radical $\mathbf{D}$ easily goes through a ring-opening to generate the alkyl radical $\mathbf{E}$, and then cyclizes with the phe- 


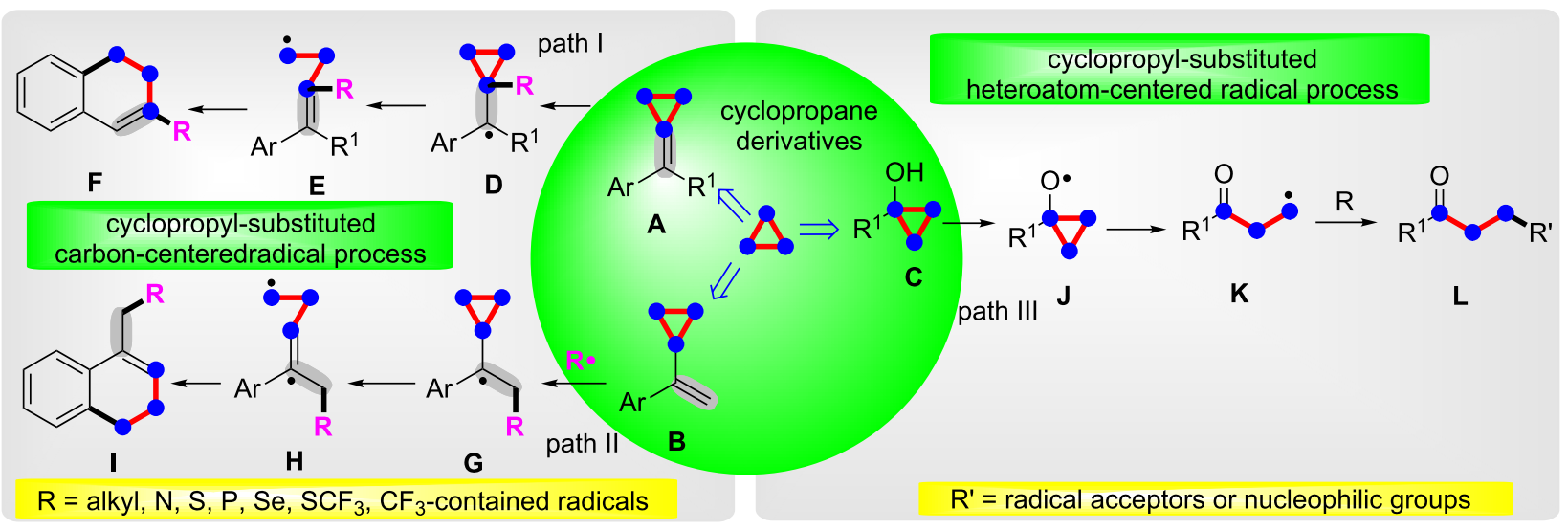

Scheme 1: The oxidative radical ring-opening/cyclization of cyclopropane derivatives.

nyl ring to afford the terminal product $\mathbf{F}$ (path I). The cyclopropyl olefins (compounds B) also react in the same cyclopropyl-substituted carbon radical pathway to finish the ringopening and cyclization transformation (path II). The cyclopropanols D firstly go through homolytic cleavage of the $\mathrm{O}-\mathrm{H}$ bond to give the oxygen-centered radical $\mathbf{J}$. The alkyl radical $\mathbf{K}$, produced by ring-opening of intermediate $\mathbf{J}$, reacts with a radical acceptor or a nucleophilic group to obtain the product $\mathbf{L}$ (path III).

Free radical reactions have flourished and became a powerful tool in organic synthesis [32-38]. With the significant potential, this strategy has captured the human's attention and solved considerable problems in the past several decades [39-42]. The free radical reaction was applied in a range of organic transformations because of its unique advantages such as excellent reactivity, mild conditions, functional group tolerance, and atom economy. A series of radicals, such as carbon, $\mathrm{Se}, \mathrm{CF}_{3}$, halogen, $\mathrm{S}$ and $\mathrm{N}$-containing radicals, were introduced into the products through oxidative radical ring-opening/cyclization of cyclopropane derivatives. In this review, we conclude recent advance in the oxidative radical ring-opening/cyclization of cyclopropane derivatives (including methylenecyclopropanes, cyclopropyl olefins and cyclopropanols) over the last 20 years.

\section{Review \\ Oxidative radical ring-opening and cycliza- tion of methylenecyclopropanes (MCPs)}

In 2004, Huang and co-workers reported the first manganese(III) acetate-mediated radical ring-opening and cyclization of methylenecyclopropanes (MCPs, 1) with malonic acid diethyl esters (2, Scheme 2) [43]. This strategy provided a novel, convenient and efficient approach to construct 2-(3,4dihydronaphthalen-2-yl)malonic acid diethyl esters 3 . The
MCPs 1 with the electron-deficient or electron-rich groups were all suitable for this reaction system. The mechanism for the $\mathrm{Mn}(\mathrm{OAc})_{3}$-mediated oxidative radical ring-opening and cyclization of MCPs with malonates is outlined in Scheme 2. Initially, the malonic acid diethyl ester (2) was transformed into radical 4 [44] under the action of $\mathrm{Mn}(\mathrm{OAc})_{3}$. Then, the selective addition of the radical 4 to the $\mathrm{C}-\mathrm{C}$ double bond of MCPs $\mathbf{1}$ formed the more stable benzyl radical intermediate $5[45,46]$, which underwent a ring-opening to generate the alkyl radical 6 [47]. Finally, the desired product 3 was generated through intramolecular cyclization of radical intermediate $\mathbf{6}$ with an aryl ring and oxidation deprotonation by another molecule $\mathrm{Mn}(\mathrm{OAc})_{3}$ [48].

Later, Shi et al. demonstrated an oxidative annulation of MCPs 1 with 1,3-dicarbonyl compounds 7 using manganese(III) catalysis under room temperature conditions, which afforded 4,5dihydrofuran derivatives $\mathbf{8}$ as $[3+2]$ annulation products (cyclopropyl retained adducts) in moderate to good yields [49]. This transformation also gave another six-membered cyclic compounds 9 (cyclopropyl opened adducts) via ring-opening and cyclization process (Scheme 3 ). However, the [3+2] annulation reaction did not occur under the standard conditions when the MCPs 1 was without an aromatic group.

The first method for direct $[3+2]$ radical cycloaddition of MCPs 1 with elemental chalcogens 10 (S, Se, Te) was developed by $\mathrm{Yu}$ and co-workers. This strategy presented a simple and efficient method for the synthesis of methylene-1,2dichalcogenolanes 11 (Scheme 4) [50]. This reaction proceeded via a radical pathway, which could take place smoothly under cartalyst- and additive-free conditions. However, the addition of the radical initiator AIBN in this reaction did not accelerate the reaction. 

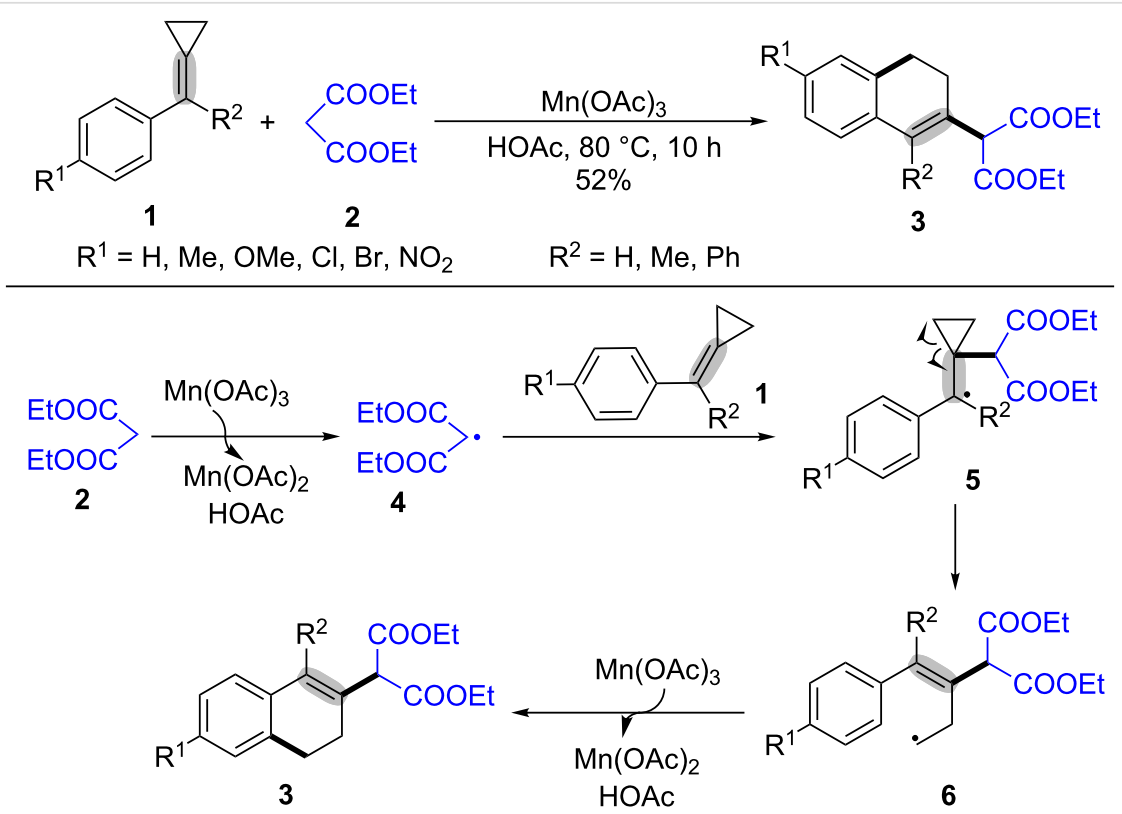

Scheme 2: $\mathrm{Mn}(\mathrm{OAc})_{3}$-mediated oxidative radical ring-opening and cyclization of MCPs with malonates.

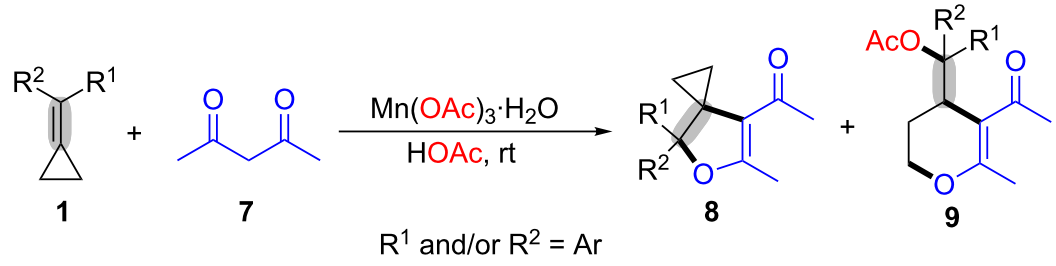

Scheme 3: Mn(III)-mediated oxidative radical ring-opening and cyclization of MCPs with 1,3-dicarbonyl compounds.

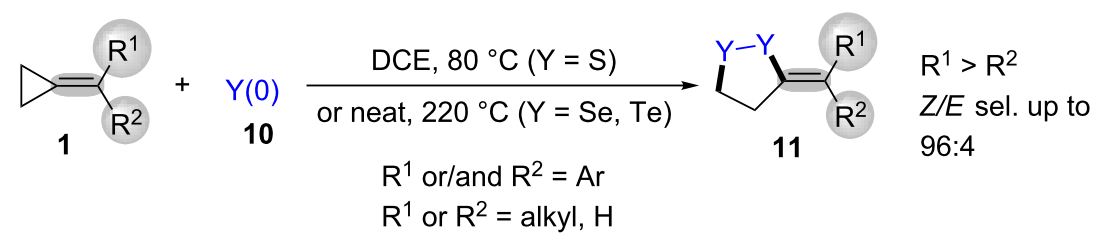

Scheme 4: Heat-promoted ring-opening/cyclization of MCPs with elemental chalgogens.

Next, Huang's group proposed the copper-catalyzed ringopening and cyclization of MCPs 1 with diphenyl diselenides 12 for the synthesis of 2-phenylseleny-3,3-diarylcyclobutenes 13 under visible light irradiation (Scheme 5) [51]. The desired products $\mathbf{1 3}$ contained a cyclobutene group and a selenium atom, which makes the products possess unique biological and pharmaceutical activities. The mechanism of the copper(II) acetate-mediated oxidative radical ring-opening/cyclization of MCPs with diphenyl diselenides is outlined in Scheme 5 . Firstly, the phenylselenyl radical 14, generated from the homolytic cleavage of diphenyl diselenide, is added to the $\mathrm{C}-\mathrm{C}$ double bond of MCPs to afford the intermediate 15, which undergoes a ring-opening process to form the radical intermediate 16 [52,53]. Then, the radical 16 reacts with copper(II) acetate to produce organocopper intermediate 17. Finally, the intramolecular insertion of $\mathrm{C}-\mathrm{Cu}$ in compounds $\mathbf{1 7}$ to the carbon-carbon double bond takes place to produce the intermediate 18 followed by $\beta$-elimination to generate the desired product 13 [54-56].

In 2005, Yu et al. described a novel and efficient oxidative radical ring-opening and cyclization of MCPs 1 with benzene- 

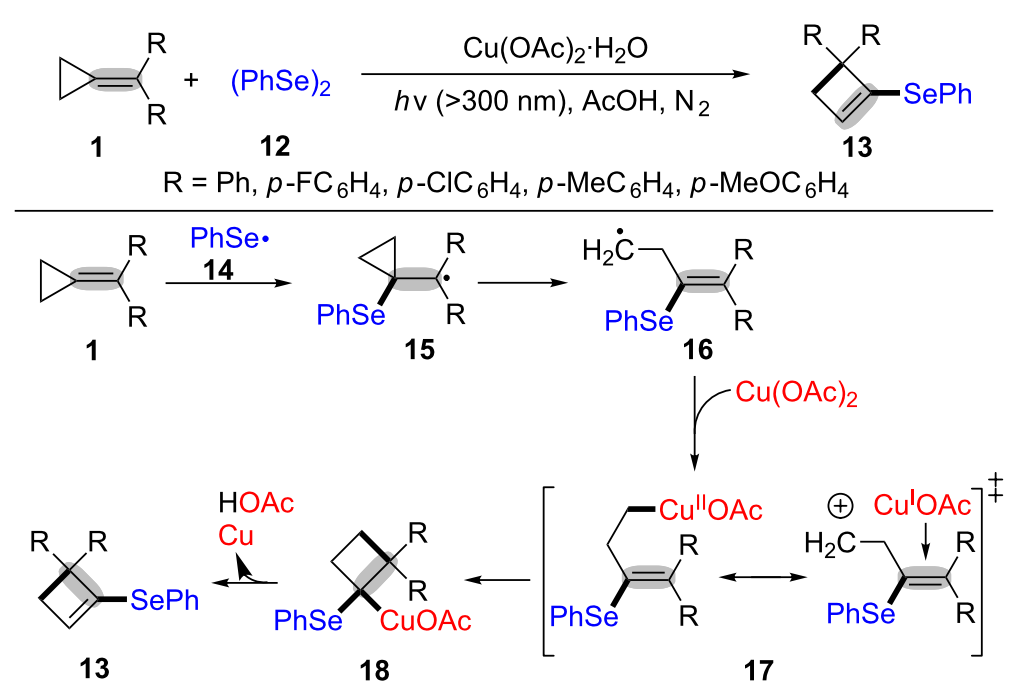

Scheme 5: Copper(II) acetate-mediated oxidative radical ring-opening and cyclization of MCPs with diphenyl diselenides.

thiol (19) for the synthesis of 3-phenylsulfanyl-1,2-dihydronaphthalenes $\mathbf{2 0}$ in moderate to good yields (Scheme 6) [57]. Additionally, using benzeneselenol instead of benzenethiol under the standard conditions generated the corresponding products in $31 \%$ yields.

In the same year, Huang's group also reported a similar ring-opening and cyclization of MCPs 1 with diethyl phosphites 21 for building diethyl 3,4-dihydro-2-naphthylphosphonates 22 (Scheme 7) [58]. This was the first example to synthesize the diethyl 3,4-dihydro-2-naphthylphosphonates 22 that have great potential applications in organic chemistry and biochemistry.

In 2009, Miao's group also discovered another method for the synthesis of 1-naphthaldehydes $\mathbf{2 5}$ under mild conditions via a radical-mediated ring-opening and intramolecular cyclization of MCPs 23 with organic selenium reagents 24 (Scheme 8) [59]. In this reaction, the MCPs with electron-withdrawing groups gave lower yields than that with electron-donating groups. Additionally, the use of other organoselenium reagents, such as phenylselenyl bromide or phenylselenyl chloride provided only

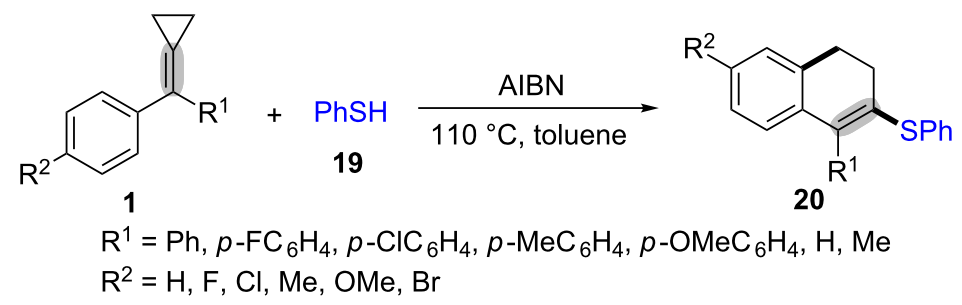

Scheme 6: AIBN-promoted oxidative radical ring-opening and cyclization of MCPs with benzenethiol.

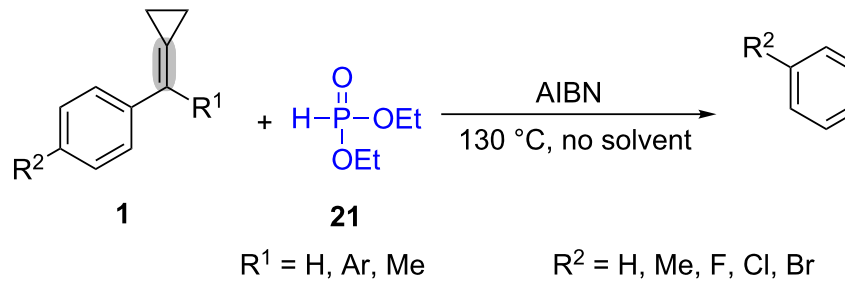




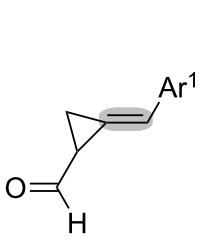

23

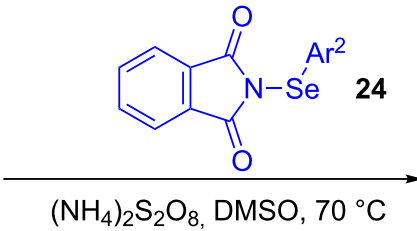

$\left(\mathrm{NH}_{4}\right)_{2} \mathrm{~S}_{2} \mathrm{O}_{8}, \mathrm{DMSO}, 70^{\circ} \mathrm{C}$

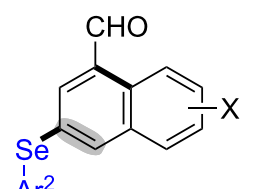

25

$\mathrm{Ar}^{1}=\mathrm{Ph}, p-\mathrm{MePh}, p-\mathrm{OMePh}, p-\mathrm{FPh}, p-\mathrm{ClPh}, p-\mathrm{BrPh}, o-\mathrm{BrPh}, o-\mathrm{OMePh}$ $\mathrm{Ar}^{2}=\mathrm{Ph}, p-\mathrm{MePh}$

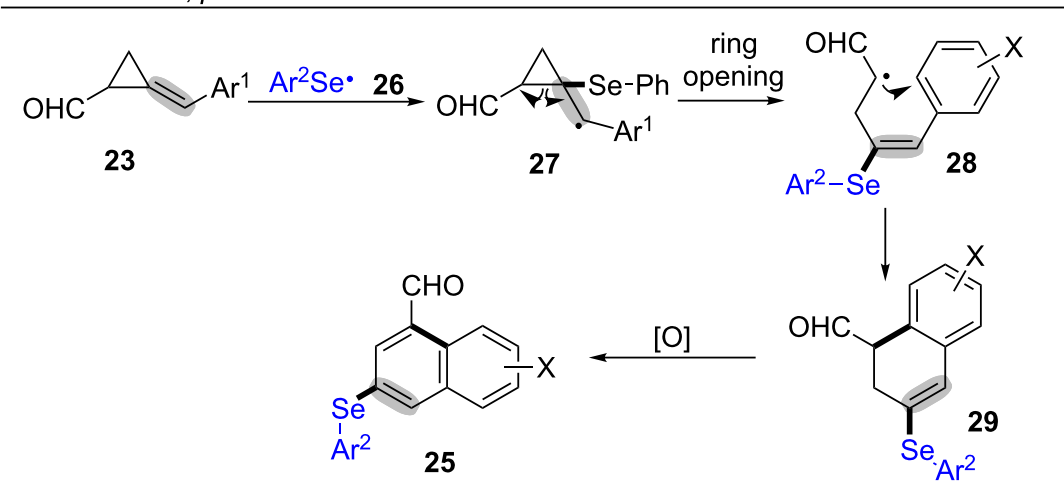

Scheme 8: Organic-selenium induced radical ring-opening and cyclization of MCPs derivatives (cyclopropylaldehydes).

trace amounts of the desired products. The mechanism for the organoselenium induced radical ring-opening and cyclization of MCPs derivatives is showed in Scheme 8. Firstly, phenylselenyl radical 26 was produced in the presence of free radical initiator $\left(\mathrm{NH}_{4}\right)_{2} \mathrm{~S}_{2} \mathrm{O}_{8}[60,61]$. Next, the intermediate $\mathbf{2 6}$ was added to the $\mathrm{C}-\mathrm{C}$ double bond of MCPs $\mathbf{2 3}$, and then went through a series of ring-opening, intramolecular cyclization, oxidation and dehydrogenation to generate 3-arylselanylnaphthaldehyde $\mathbf{2 5}$.

In 2015, Shi and co-workers reported a novel and efficient method to construct $\mathrm{CF}_{3}$-substituted dihydronaphthalene derivatives 31 in moderate to excellent yields under mild conditions through the $\mathrm{Cu}(\mathrm{I})$-catalyzed trifluoromethylation/ring-opening/ cyclization of MCPs 1 with Togni reagent II (30, Scheme 9) [62]. In this transformation, many substituted MCPs 1 with alkyl groups, Ts-protected amino groups, or halogens were tolerated well and gave the desired products $\mathbf{3 1}$ in good yields. Moreover, the product 31a could go through a further oxidation to afford two different products in the presence of different amount of NBS ( $N$-bromosuccinimide). The corresponding $\mathrm{CF}_{3}$-substituted naphthalene 32 could be obtained in $69 \%$ yield when the product 31a was oxidized by 3 equiv of NBS (Scheme 9, reaction a). When the amount of NBS was increased to 6 equiv under identical conditions, the $\mathrm{CF}_{3}$-substituted naphthaldehyde 33 was obtained in 61\% yield (Scheme 9, reaction b). Furthermore, the product 31a could also be transformed to the $\mathrm{CF}_{3}$-substituted epoxide 34 in the presence of 2 equiv $m$-CPBA ( $m$-chloroperbenzoic acid) (Scheme 9, reac- tion c). A radical-trapping experiment was conducted with the addition of TEMPO or BHT under the standard conditions, and the reactions were suppressed by radical scavengers, which suggested that the reaction underwent a radical process. The proposed mechanism is depicted in Scheme 9. Initially, the $\mathrm{CF}_{3}$ radical 35 is generated from the Togni reagent II (30) under the action of $\mathrm{Cu}(\mathrm{I})[63,64]$. Then the $\mathrm{CF}_{3}$ radical 35 adds to the $\mathrm{C}-\mathrm{C}$ double bond in MCPs $\mathbf{1}$ to give the more stable benzyl radical intermediate 36 which went through a ring-opening process to provide the alkyl radical intermediate 37 . The intermediate 37 undergoes intramolecular cyclization with the aromatic ring to generate intermediate $\mathbf{3 8}$ which is oxidized by $\mathrm{Cu}$ (II) to provide the $\mathrm{CF}_{3}$-substituted dihydronaphthalenes derivatives $\mathbf{3 1}$ along with releasing a proton $[65,66]$.

The trifluoromethylthiolation of MCPs 1 with $\mathrm{AgSCF}_{3}$ was achieved by Shi et al. which proceeds through a sequence of radical addition, ring-opening, cyclization, oxidation and dehydrogenation and successfully furnished trifluoromethylthiolated 1,2-dihydronaphthalene derivatives 39 (Scheme 10) [67]. This reaction was achieved in the presence of 3.0 equiv of $\mathrm{Na}_{2} \mathrm{~S}_{2} \mathrm{O}_{8}$ as the oxidants, 0.5 equiv of HMPA $\left(N, N, N^{\prime}, N^{\prime}, N^{\prime \prime}, N^{\prime \prime}\right.$-hexamethylphosphorotriamide) as the additive in DMSO.

With a similar oxidative radical ring-opening and cyclization strategy, our group developed a novel method for ring-opening and cyclization of MCPs $\mathbf{1}$ with ethers $\mathbf{4 0}$ afforded 2-substituted 3,4-dihydronaphthalenes $\mathbf{4 1}$ in moderate to excellent 
<smiles>[R]C1=C(C(F)(F)F)CCc2cc[R]([H])cc21</smiles>

$\mathrm{R}^{1}=\mathrm{H}, \mathrm{Ph}$

30

31

$\mathrm{R}^{2}=\mathrm{CH}_{2} \mathrm{NHTs}, \mathrm{NHTs}, \mathrm{NO}_{2}, \mathrm{CN}, \mathrm{OBn}, \mathrm{OMe}, \mathrm{X} \quad 16$ examples up to $83 \%$ yield

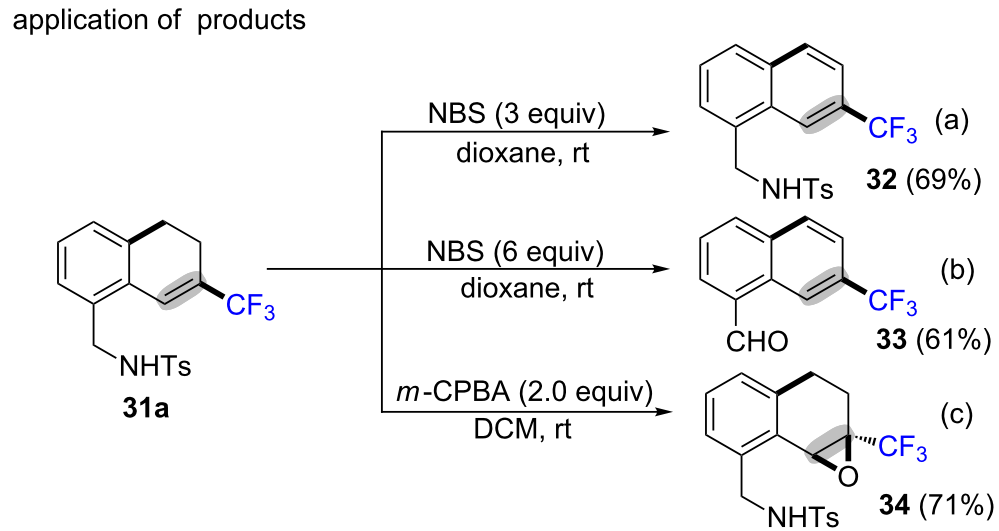

mechanistic investigations
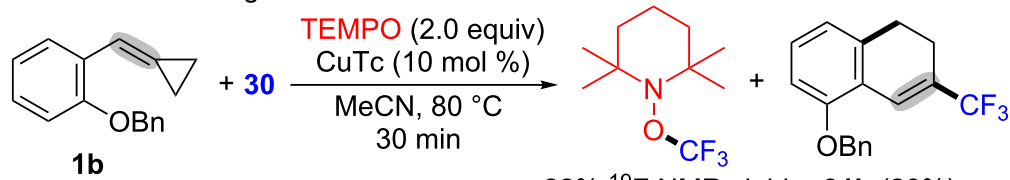

$22 \%{ }^{19} \mathrm{~F}$ NMR yield

$31 \mathrm{~b}(28 \%)$

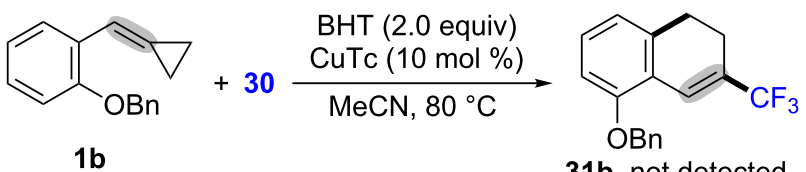

1b

31b, not detected

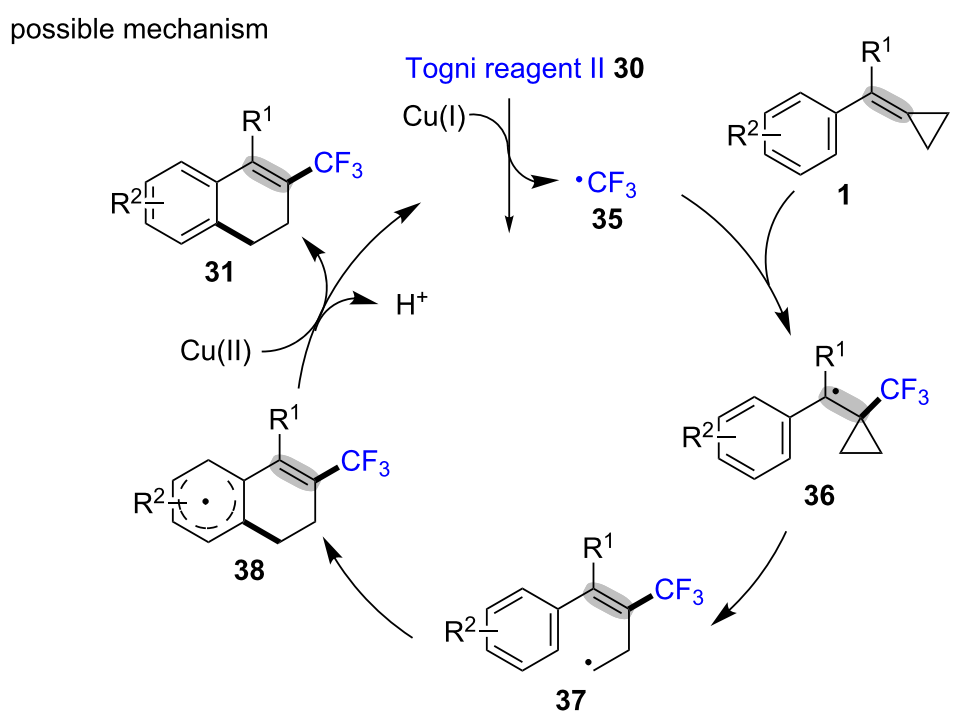

Scheme 9: Copper(I)-catalyzed oxidative radical trifluoromethylation/ring-opening/cyclization of MCPs with Togni reagent II.

yields (Scheme 11) [68]. This transformation just needed 2 equiv of TBHP (42), avoiding using transition metal catalysts, ligands, and bases. In the proposed mechanism (Scheme 11), the tert-butoxyl radical $\mathbf{4 3}$, which was formed from THBP (42) under heating conditions, attackes the ether $\mathbf{4 0}$ to afford the radical 44 [69-72]. Next, the addition of radical 44 to the $\mathrm{C}-\mathrm{C}$ 

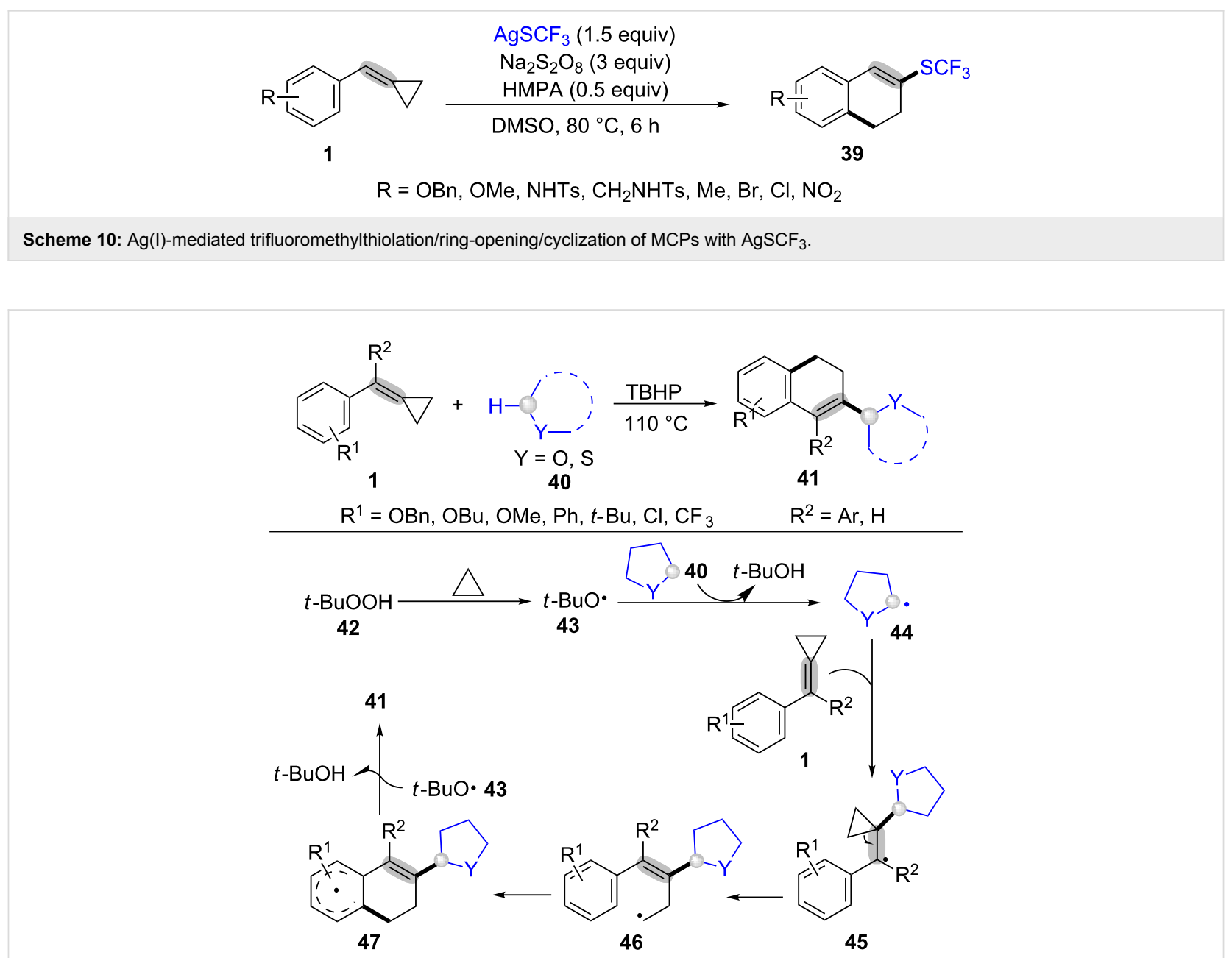

Scheme 11: oxidative radical ring-opening and cyclization of $M C P s$ with $\alpha-C\left(s^{3}\right)--H$ of ethers.

double bond of MCPs $\mathbf{1}$ generats a more stable benzyl radical 45. Final ring-opening, intramolecular cyclization, oxidation, and dehydrogenation finally delivers the desired product $\mathbf{4 1}$.

Next, our group reported the first oxidative ring-opening and cyclization between MCPs $\mathbf{1}$ and aldehydes $\mathbf{4 8}$ to provide 2-acyl-3,4-dihydronaphthalenes $\mathbf{4 9}$ in moderate to excellent yields via a series of radical addition, ring-opening and cyclization in the presence of DTBP (di-tert-butyl peroxide) and Lewis acids (Scheme 12) [73]. Moreover, the experimental results showed MCPs 1 with electron-rich aryl groups could deliver higher yields than that with electron-deficient ones. As outlined in Scheme 12, a tert-butoxy radical and a methyl radical were generated from cleavage of DTBP at the reaction temperature. Aldehyde 48 is easily transformed into acyl radical $\mathbf{5 0}$ in the presence of an alkoxy radical or a methyl radical [74-77]. The acyl radical $\mathbf{5 0}$ adds to the $\mathrm{C}-\mathrm{C}$ double bond of MCPs giving the benzyl radical intermediate 51. The ring-opening of radical intermediate $\mathbf{5 1}$ occurres to form the alkyl radical intermediate
52 which intermolecularly cyclizes with the aryl ring. The following oxidation and dehydrogenation gives the target product 49.

A new and first achievement for the synthesis of $\mathrm{CF}_{3}$-contained seven-membered ring compounds 55 and 56 through trifluoromethylation of acrylamide-tethered alkylidenecyclopropanes 54 was presented by Shi and co-workers (Scheme 13) [78]. The possible reaction pathway is outlined in Scheme 13. Initially, the Togni reagent II (30) goes through a single-electron transfer (SET) under the action of $\mathrm{Fe}^{2+}$ to generate the $\mathrm{CF}_{3}$ radical 35 . The $\mathrm{CF}_{3}$ radical 35 is trapped by the $\mathrm{C}-\mathrm{C}$ double bond of substrate 54 to produce the alkyl radical intermediate 57 . Then, the intramolecular addition of an alkyl radical to the less hindered central carbon of MCPs $\mathbf{5 4}$ gives the benzyl radical intermediate 58, which undergoes a ring-opening process to provide the alkyl radical intermediate 59 [79,80]. Because of the different substituent groups on the MCPs $\mathbf{5 4}$ (whether $\mathrm{R}^{1}$ was a para-methoxy substituent or not), this reaction proceeds through two 

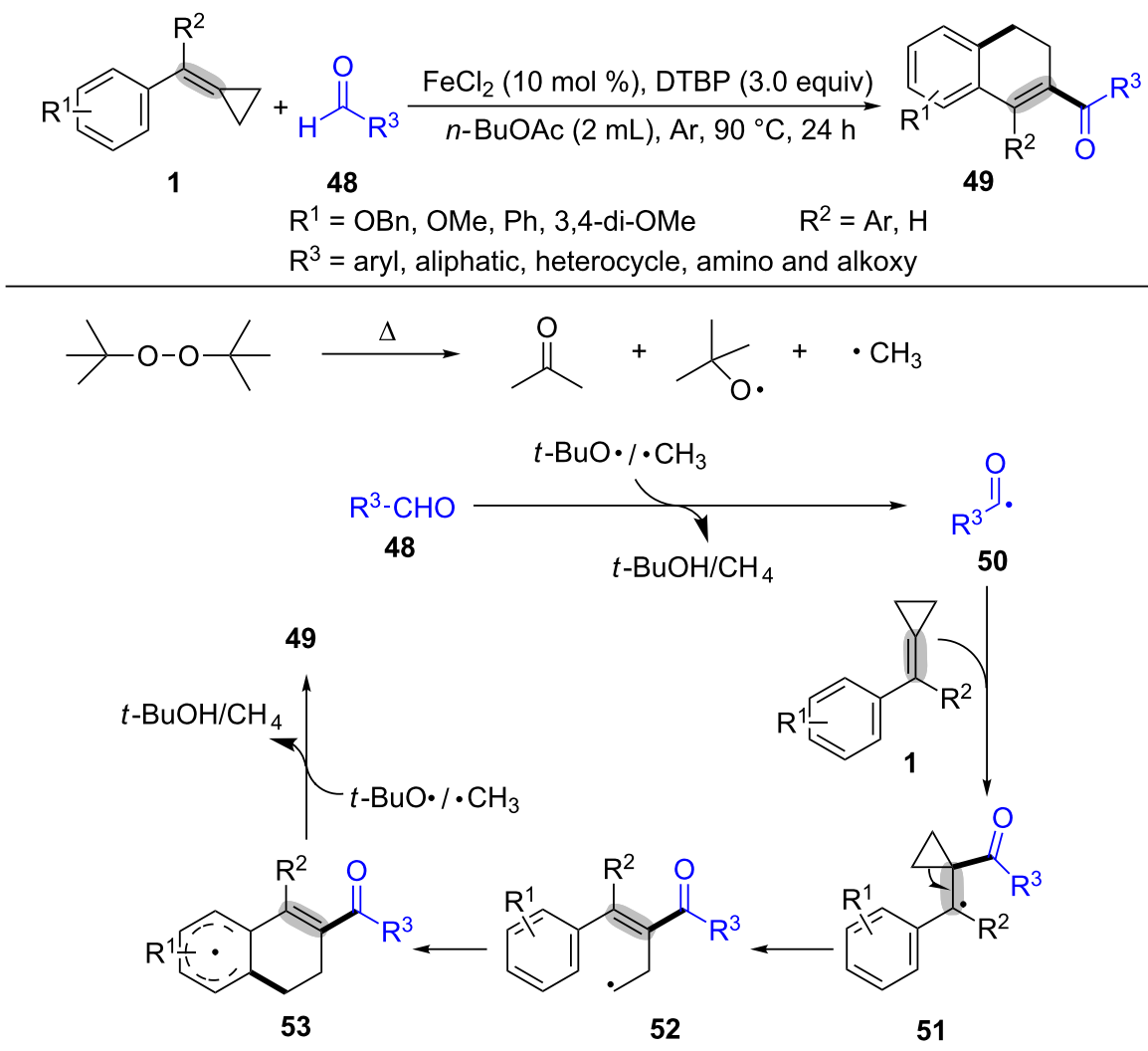

Scheme 12: Oxidative radical ring-opening and cyclization of MCPs with aldehydes.

different pathways. When $\mathrm{R}^{1}$ is not a para-methoxy group, the intermediate $\mathbf{5 9}$ undergoes a conventional cyclization with aromatic ring to afford the radical intermediate $\mathbf{6 0}$. After oxidation and aromatization, the corresponding product $\mathbf{5 5}$ is formed. An ipso-cyclization with aromatic ring occurres and gives the intermediate $\mathbf{6 1}$ when $\mathrm{R}^{1}$ is a para-methoxy group. The oxonium ion $\mathbf{6 2}$ is produced by the oxidation of the intermediate $\mathbf{6 1}$ under the action of $\mathrm{Fe}^{3+}$ [81]. Lastly, the oxonium ion $\mathbf{6 2}$ is transformed into the desired product $\mathbf{5 6}$ in the presence of 2 -indobenzoic acid anion.

Recently, Shi's group developed the first ring expansion of MCPs 63 with a nitrogen atom to furnish azetidines 64 (Scheme 14) [82]. The author proposed that $\mathrm{Rh}(\mathrm{II})$ had an effective impact on the reactions and could improve the reaction yields. Unfortunately, the MCPs $\mathbf{6 3}$ with the groups $\mathrm{R}^{1}$ and $\mathrm{R}^{2}=\mathrm{H}$ were not suitable for this transformation. The reason was because the formed intermediate was unstable under this conditions. A possible mechanism is outlined in Scheme 14 Initially, the Rh-nitrene intermediate 65 [83-86] is generated from the coordination of azide to $\mathrm{Rh}_{2}(\mathrm{esp})_{2}$ complex (bis[rhodium-( $\alpha, \alpha, \alpha^{\prime}, \alpha^{\prime}$-tetramethyl-1,3-benzenedipropionic acid)]) and extrusion of $\mathrm{N}_{2}$. Then, the Rh-nitrene intermediate $\mathbf{6 5}$ goes through an intramolecular single electron transfer
(SET) to give the nitrogen-centered radical intermediate 66 [8790]. Next, the radical addition of intermediate $\mathbf{6 6}$ to the $\mathrm{C}-\mathrm{C}$ double bond in MCPs moiety furnishes the more stable benzyl radical intermediate $\mathbf{6 7}$, which is ring-opened to give alkyl radical 68. Finally, intermediate $\mathbf{6 8}$ goes through SET with the $\mathrm{Rh}(\mathrm{III})$ species and intramolecular cyclization with the 2-position of the indole moiety to afford the target product 64 along with the regenerated $\mathrm{Rh}(\mathrm{III})$ catalyst.

A silver-catalyzed intramolecular cascade amination/ringopening/cyclization of a variety of substituted MCPs 69 was proposed by Fan and co-workers, which provided a simple and efficient way for the building of [2,3-c]dihydrocarbazoles 70 and [2,3-c]carbazoles 71 (Scheme 15) [91]. This process permitted the use of readily available and cheap AgOAc as the catalyst and oxidant, and DMF as the solvent. Notably, the product 70 was easily transformed into $\mathbf{7 1}$ in the presence of chloranil ( 1.4 equiv) at $120{ }^{\circ} \mathrm{C}$ under Ar atmosphere for $5 \mathrm{~h}$. In this transformation, substrates with electron-donating groups showed higher yields than the ones with electron-withdrawing groups.

In the same year, Shi et al. reported an effective ring-opening and cyclization of arylvinylidenecyclopropanes $\mathbf{7 2}$ with diaryl 


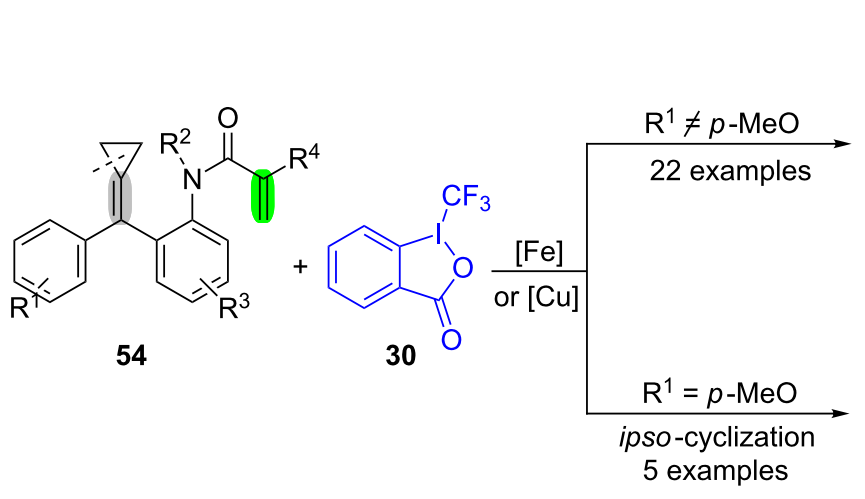

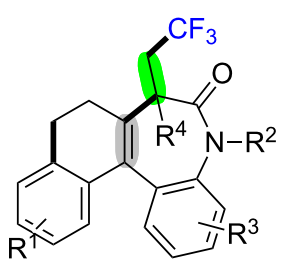

55

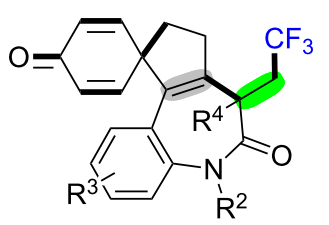

56

$\mathrm{R}^{3}=\mathrm{OMe}, \mathrm{Cl}, \mathrm{NO}_{2}$, $\mathrm{R}^{4}=\mathrm{Me}, \mathrm{Ph}, \mathrm{H}$

$\mathrm{R}^{2}=\mathrm{H}, \mathrm{Me}, \mathrm{Et}, \mathrm{Bn}$, allyl, Ts

possible mechanism<smiles>[R][R]#CC(=C)C(=O)N([R2])c1ccccc1C(=C1CC1)c1ccccc1</smiles><smiles>CCCC(C)C</smiles><smiles>[R][R]1cccc(C(=C2CC2)c2ccccc2N([R])C(=O)C([R4])=CC(F)(F)F)c1</smiles>

57

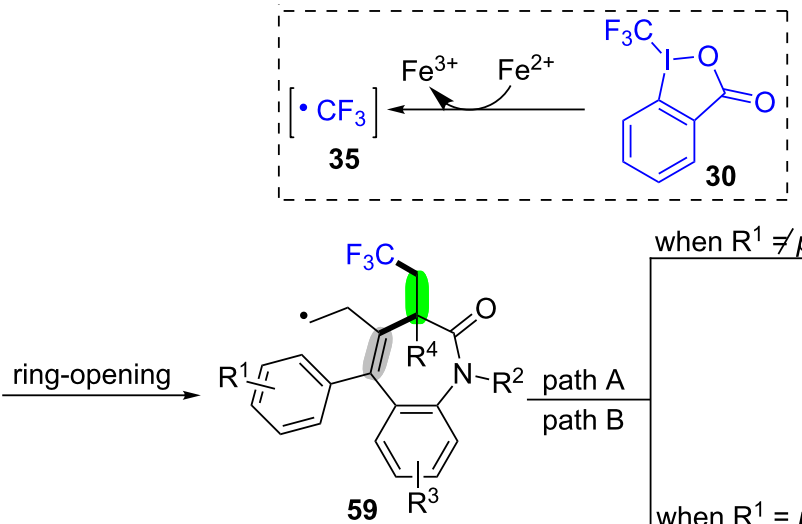

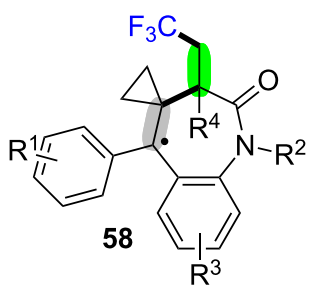
when $\mathrm{R}^{1} \neq p-\mathrm{MeO}$

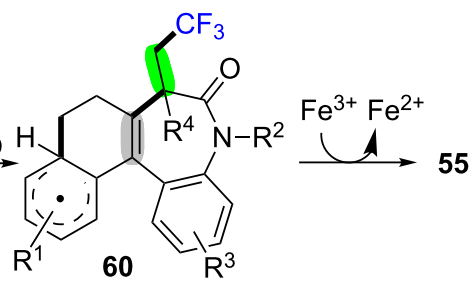

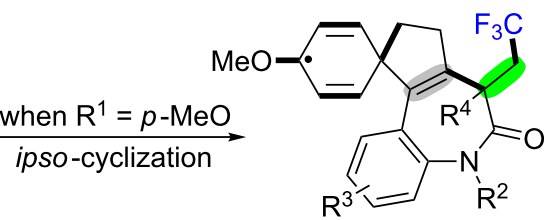<smiles>[10BH]</smiles>

61<smiles>CCOC(=O)C(C)(C)C</smiles>

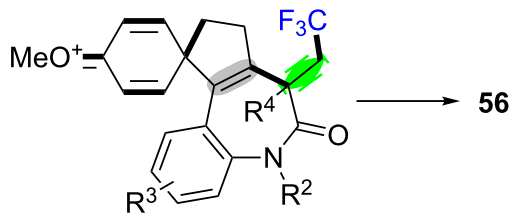

62

Scheme 13: $\mathrm{Cu}(\mathrm{I})$ or $\mathrm{Fe}(\mathrm{II})$-catalyzed oxidative radical trifluoromethylation/ring-opening/cyclization of MCPs derivatives (acrylamide-tethered alkylidenecyclopropanes).

diselenides $\mathbf{7 3}$ for the synthesis of 1,2-diarylselenocyclopentene 74 in moderate to good yields at $150{ }^{\circ} \mathrm{C}$ for $1.5 \mathrm{~h}$ (Scheme 16) [92]. The electron-rich, electron-neutral and elec- tron-poor arylvinylidenecyclopropanes were tolerated well in this transformation. The detailed mechanism is outlined in Scheme 16. Initially, the homolysis of diphenyldiselenide $\mathbf{7 3}$ 


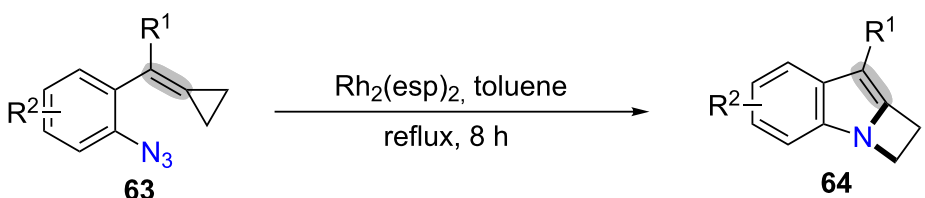

63

$\mathrm{R}^{1}=\mathrm{Ar}, \mathrm{Me}, \mathrm{H} \quad \mathrm{R}^{2}=\mathrm{H}, 5-\mathrm{Cl}, 4-\mathrm{OMe}$

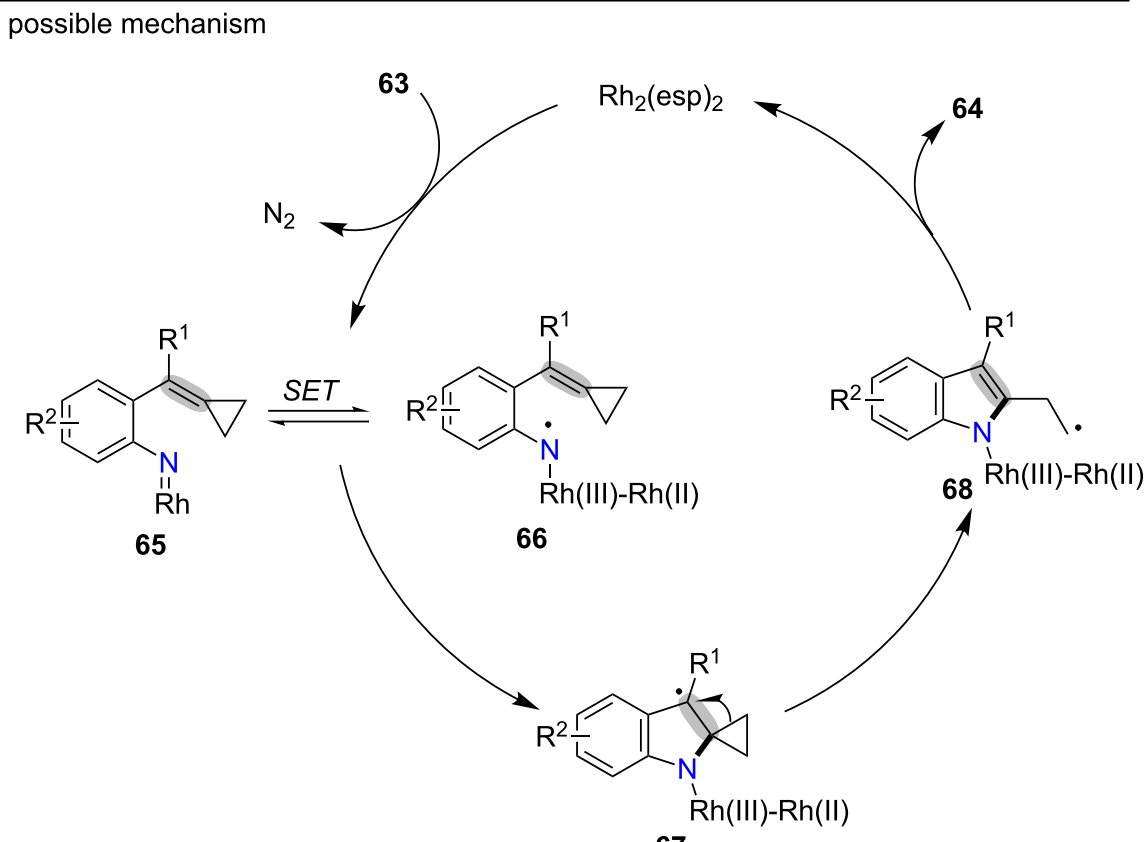

67

Scheme 14: $\mathrm{Rh}(\mathrm{II})$-catalyzed oxidative radical ring-opening and cyclization of MCPs.

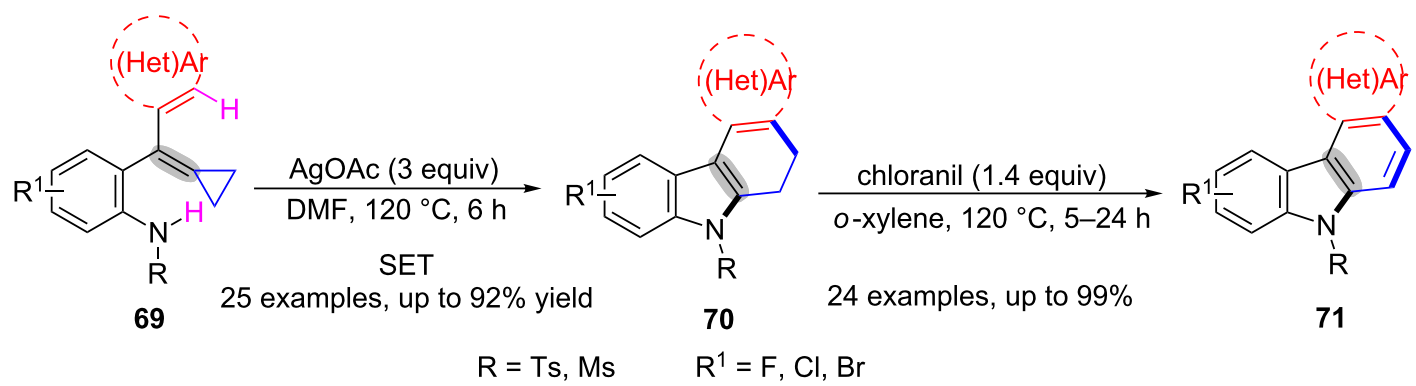

Scheme 15: $\mathrm{Ag}(\mathrm{I})$-catalyzed oxidative radical amination/ring-opening/cyclization of MCPs derivatives.

under heating conditions produces the phenylseleno radical 26 [93]. Then, the additon of radical $\mathbf{2 6}$ to the $\mathrm{C}-\mathrm{C}$ double bond of MCPs derivatives 72 affords the radical intermediate 75 [94]. Next, the radical $\mathbf{7 5}$ goes through a ring-opening process to give the radical intermediate $\mathbf{7 6}$. The intermediate $\mathbf{7 7}$, produced by the intramolecular cyclization of intermediate 76, reactes with diphenyl diselenide $\mathbf{7 3}$ to form the target product $\mathbf{7 4}$ via homolytic substitution $\left(\mathrm{S}_{\mathrm{H}}\right)$.

In 2013, Ryu and co-workers developed the bromine radicalmediated ring-opening and alkylation of alkylidenecyclo- propanes 1 with allylic bromides $\mathbf{7 8}$ for the synthesis of 2-bromo-1,6-dienes 79 via radical ring-opening and $\mathrm{S}_{\mathrm{H}} 2$ ' reactions (path V in Scheme 17) [95]. The experimental results suggested that radical carbonylation could also be incorporated in the reaction sequence, leading to 2-bromo-1,7-dien-5-ones 80 (path IV in Scheme 17).

In 2016, Xu's group exploited the fluoroalkyl $\left(\mathrm{R}_{\mathrm{F}}\right)$ radicalmediated ring-opening of MCPs $\mathbf{1}$ for the synthesis of fluorinated homoallylic compounds (80 and 81, Scheme 18) [96]. In this reaction system, the radical reaction of MCPs $\mathbf{1}$ with $\mathrm{R}_{\mathrm{F}}-\mathrm{X}$ 
<smiles>[R]C([R])=C=C1CC1[R]</smiles>

72

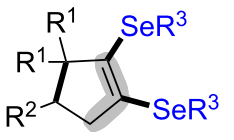

74

$\mathrm{R}^{1}=p-\mathrm{MeC}_{6} \mathrm{H}_{4}, p-\mathrm{MeOC}_{6} \mathrm{H}_{4}, p-\mathrm{FC}_{6} \mathrm{H}_{4}, p-\mathrm{ClC}_{6} \mathrm{H}_{4}, \mathrm{Ph}$

$\mathrm{R}^{2}=\mathrm{Ph}, p-\mathrm{MeC}_{6} \mathrm{H}_{4}, p-\mathrm{MeOC}_{6} \mathrm{H}_{4}, p-\mathrm{ClC}_{6} \mathrm{H}_{4}$

$\mathrm{R}^{3}=\mathrm{Ph}, p-\mathrm{MeC}_{6} \mathrm{H}_{4}, p-\mathrm{MeOC}_{6} \mathrm{H}_{4}$

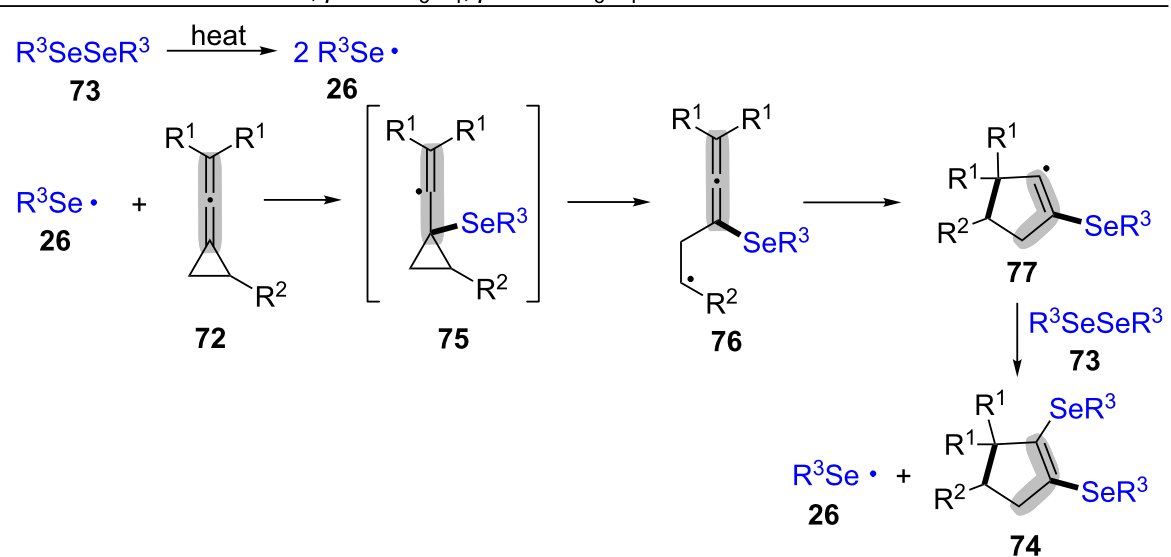

Scheme 16: Heating-promoted radical ring-opening and cyclization of MCP derivatives (arylvinylidenecyclopropanes) with diaryl diselenides.

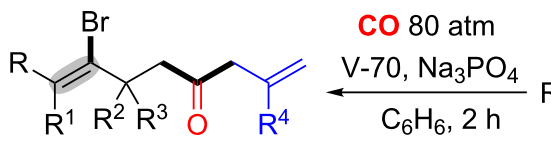

80

path IV

$\mathrm{R}$ and/or $\mathrm{R}^{1}=$ alkyl<smiles>[R]C([R])=C1CC1([R])[R]</smiles>

$\mathrm{R}^{2}$ and/or $\mathrm{R}^{3}=\mathrm{H}$

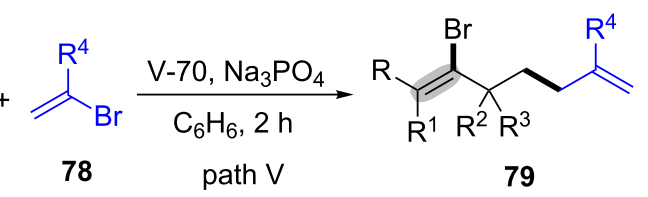

$\mathrm{R}^{4}=\mathrm{H}$, COOEt, $\mathrm{CN}, \mathrm{Ph}$

Scheme 17: Bromine radical-mediated ring-opening of alkylidenecyclopropanes.

$(\mathrm{X}=\mathrm{Br}, \mathrm{I})$ furnished homoallylic halides in excellent yields (path VII in Scheme 18). Similarly, the radical reaction of MCPs 1 with the $\mathrm{R}_{\mathrm{F}} \mathrm{TMS} / \mathrm{CsF} / \mathrm{PhI}(\mathrm{OAc})_{2}$ gave homoallylic acohol esters in moderate to good yields (path VI in Scheme 18).

\section{Oxidative radical ring-opening and cycliza- tion of cyclopropyl olefins}

In 2016, Li's group reported a photoredox catalysis oxidative radical ring-opening and cyclization of cyclopropyl olefins $\mathbf{8 3}$ with bromides 84 for the synthesis of partially saturated naphthalenes 85 in moderate to excellent yields (Scheme 19) [97]. It was the first example for alkylation, ring-opening and cyclization cascade reaction of the cyclopropyl olefins under photoredox catalysis. The alkylation reagents could be extended to other bromides, such as monofluoro-substituted bromides, trifluoro-substituted bromides, bromoacetonitrile and bromomalonate. This alkylation/ring-opening/cyclization was carried out by using $\operatorname{Ir}(\mathrm{ppy})_{2}$ (dtbbpy) $\mathrm{PF}_{4}$ as photocatalyst, and $\mathrm{K}_{2} \mathrm{HPO}_{4}$ as base in $\mathrm{MeCN}$ under the irradiation of $24 \mathrm{~W}$ blue LED light at<smiles></smiles>

$\mathrm{R}=\mathrm{Me}, t-\mathrm{Bu}$

\section{$\frac{\mathrm{Phl}(\mathrm{OCOR})_{2}(1.5 \text { equiv) }}{\mathrm{CsF} \text { (3 equiv), NaOAc (1 equiv) }}$ $\mathrm{CH}_{3} \mathrm{CN}, \mathrm{rt}, 3 \mathrm{~h}$} path $\mathrm{VI}$

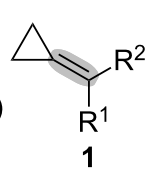

$\mathrm{R}^{1}=\mathrm{R}^{2}=$ alkyl

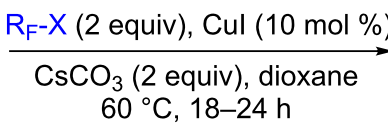
path VII<smiles>[X]CCC([R7])=C([R])[B]Br</smiles>

$\mathrm{R}_{\mathrm{F}}=\mathrm{C}_{4} \mathrm{~F}_{9}, \mathrm{CF}_{2} \mathrm{COOEt}$

Scheme 18: Fluoroalkyl (Rf) radical-mediated ring-opening of MCPs. 
<smiles>C=C(c1cc[R1]cc1)C1CC1</smiles>

83
$\operatorname{Ir}(\text { ppy })_{2}\left(\right.$ dtbbpy) $\mathrm{PF}_{4}(1 \mathrm{~mol} \%)$<smiles></smiles>

84

$\underset{\mathrm{K}_{2} \mathrm{HPO}_{4}(1.2 \text { equiv) }}{\mathrm{CH}_{3} \mathrm{CN}(2 \mathrm{~mL})}$

$24 \mathrm{~W}$ blue LED light, $\mathrm{rt}$

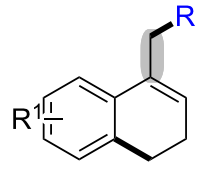

85

$\mathrm{R}=\mathrm{F}_{2} \mathrm{CCONEt}_{2}, \mathrm{~F}_{2} \mathrm{CCONHPh}, \mathrm{FCHCOOEt}, \mathrm{CF}_{3}, \mathrm{CH}_{2} \mathrm{CN}, \mathrm{CH}(\mathrm{COOEt})_{2}$ $\mathrm{R}^{1}=\mathrm{H}, \mathrm{Me}$, OMe, $\mathrm{F}, \mathrm{Cl}, \mathrm{Br}, \mathrm{CF}_{3}$

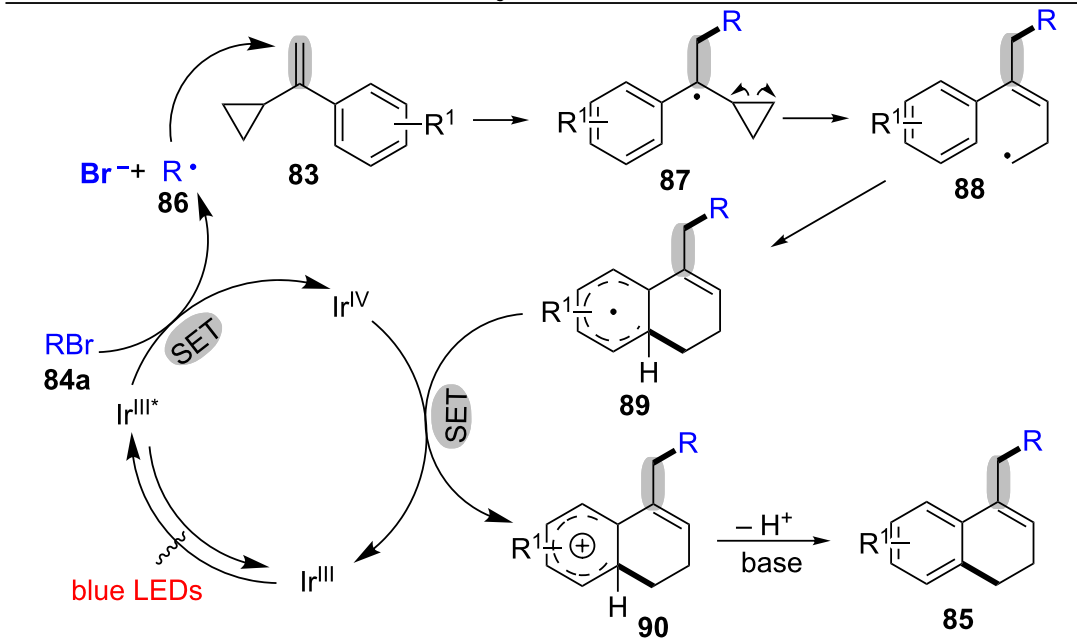

Scheme 19: Visible-light-induced alkylation/ring-opening/cyclization of cyclopropyl olefins with bromides.

room temperature for $12-36 \mathrm{~h}$. A plausible mechanism is shown in Scheme 19. Firstly, the substrate 84a underwent oxidative quenching under the action of an iridium photoredox catalyst to afford the alkyl radical $\mathbf{8 6}$, which adds to the $\mathrm{C}-\mathrm{C}$ double bond of MCPs $\mathbf{8 3}$ to deliver the benzyl radical $\mathbf{8 7}$. Then, it undergoes a ring-opening process to afford the terminal alkyl radical $\mathbf{8 8}$. Next, the alkyl radical $\mathbf{8 8}$ intramolecular cyclizes with the phenyl ring to give intermediate 89. Finally, the resulting aryl radical intermediate $\mathbf{8 9}$ is oxidized and deprotonated to provide the target product $\mathbf{8 5}$. In the process, two new $\mathrm{C}-\mathrm{C}$ bonds and a new ring are formed.

\section{Oxidative radical ring-opening of cyclo- propanols}

In 2011, Chiba's group presented Mn(III)-mediated ringopening and [3+3]-annulation of cyclopropanols 91 and vinyl azides 92 for the synthesis of azaheterocyles 93 (Scheme 20) [98]. This strategy could also be applied to the synthesis of the quaternary indole alkaloid and melinonine-E.

Quinones play an important role in organic chemistry because of their unique structure. In 2013, Malayappasamy and co-workers reported an efficient and convenient method for the synthesis of $\gamma$-carbonyl quinones 95 via ring-opening and functionalization of cyclopropanols 91 with quinones 94 (Scheme 21) [99]. In this transformation, both $\mathrm{AgNO}_{3}$ and $\mathrm{FeSO}_{4}$ were all efficient catalysts for the ring-opening and functionalization reaction. However, $\mathrm{AgNO}_{3}$ was superior than $\mathrm{FeSO}_{4}$ according to the reaction yields and time. Interestingly, aromatic cyclopropanols delivered higher yields than aliphatic ones. The mechanism for the $\mathrm{Ag}(\mathrm{I})$-catalyzed oxidative ringopening and functionalization of cyclopropanols with quinones

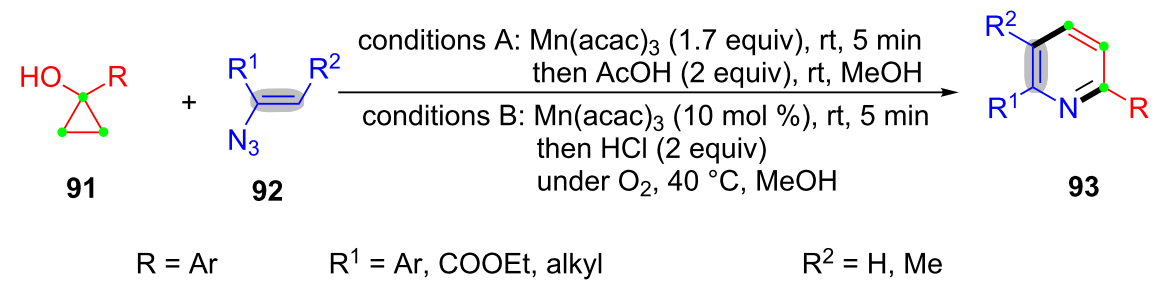

Scheme 20: $\mathrm{Mn}(\mathrm{III})$-mediated ring-opening and [3 + 3]-annulation of cyclopropanols and vinyl azides. 

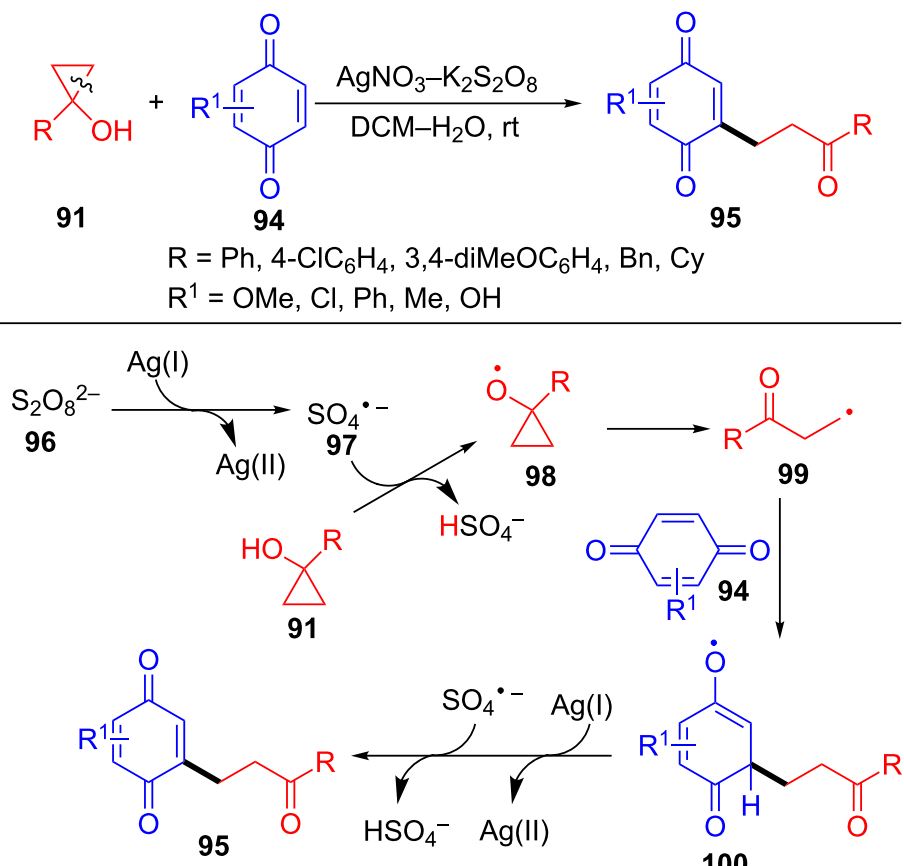

Scheme 21: $\mathrm{Ag}(\mathrm{I})$-catalyzed oxidative ring-opening of cyclopropanols with quinones.

is outlined in Scheme 21. Firstly, the sulfate radical anion 97 is generated from persulfate 96 under the action of $\mathrm{Ag}(\mathrm{I})$. Next, the radical 97 reacts with cyclopropanol 91 to give the cyclopropoxy radical $\mathbf{9 8}$, which undergoes a ring-opening process to produce $\beta$-keto radical $\mathbf{9 9}$. The radical $\mathbf{1 0 0}$ is formed through the addition of radical 99 to the quinones $\mathbf{9 4}$. Finally, the intermediate $\mathbf{1 0 0}$ occurres reoxidation with $\mathrm{Ag}(\mathrm{II})$ to provide the final product 95 along with regenerated $\mathrm{Ag}(\mathrm{I})$.

In 2015, Duan et al. developed a Ag(I)-catalyzed oxidative ringopening of cyclopropanols 91 with heteroarenes 101 or $\mathbf{1 0 3}$ for the synthesis of carbonyl-containing alkyl-substituted heteroarenes $\mathbf{1 0 2}$ or $\mathbf{1 0 4}$ under mild conditions in moderate to good yields with good functional group tolerance (Scheme 22) [100]. This reaction went through a selective $\mathrm{C}\left(\mathrm{sp}^{3}\right)-\mathrm{C}\left(\mathrm{sp}^{3}\right)$ bond cleavage, $\mathrm{C}-\mathrm{H}$ activation and $\mathrm{C}\left(\mathrm{sp}^{3}\right)-\mathrm{C}\left(\mathrm{sp}^{2}\right)$ bond formation. Notably, this finding was the first example for silver-catalyzed regioselective $\mathrm{C} 2$-alkylation of heterorarenes with primary alkyl radicals, generated from cyclopropanols through a radical ring-opening process.

Lopp's group also reported an efficient approach for copper-catalyzed ring-opening and trifluoromethylation of cyclopropanols 91 to construct $\beta$-trifluoromethyl-substituted ketones $\mathbf{1 0 6}$ (Scheme 23) [101]. Additionally, a series of cyclopropanols with different functional $\mathrm{R}$ groups were successfully scaled up to $1 \mathrm{mmol}$. In this transformation, there exist two possible pathways to produce the target product $\mathbf{1 0 6}$. The Togni reagent (105) reacts with $\mathrm{CuCl}$ to generate $\mathrm{Cu}(\mathrm{III})$ complex 108. Then, the intermediated $\mathbf{1 0 9}$ is generated from the electrophilic attack

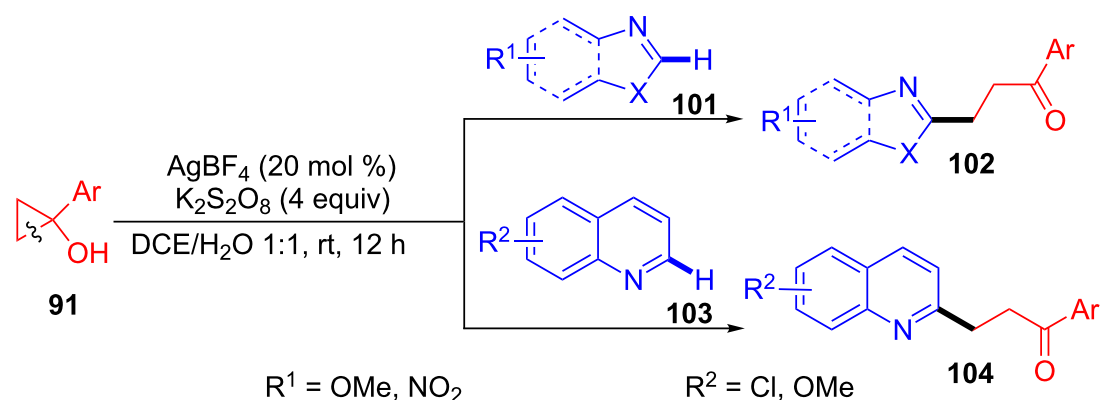

Scheme 22: $\mathrm{Ag}(\mathrm{I})$-catalyzed oxidative ring-opening of cyclopropanols with heteroarenes. 

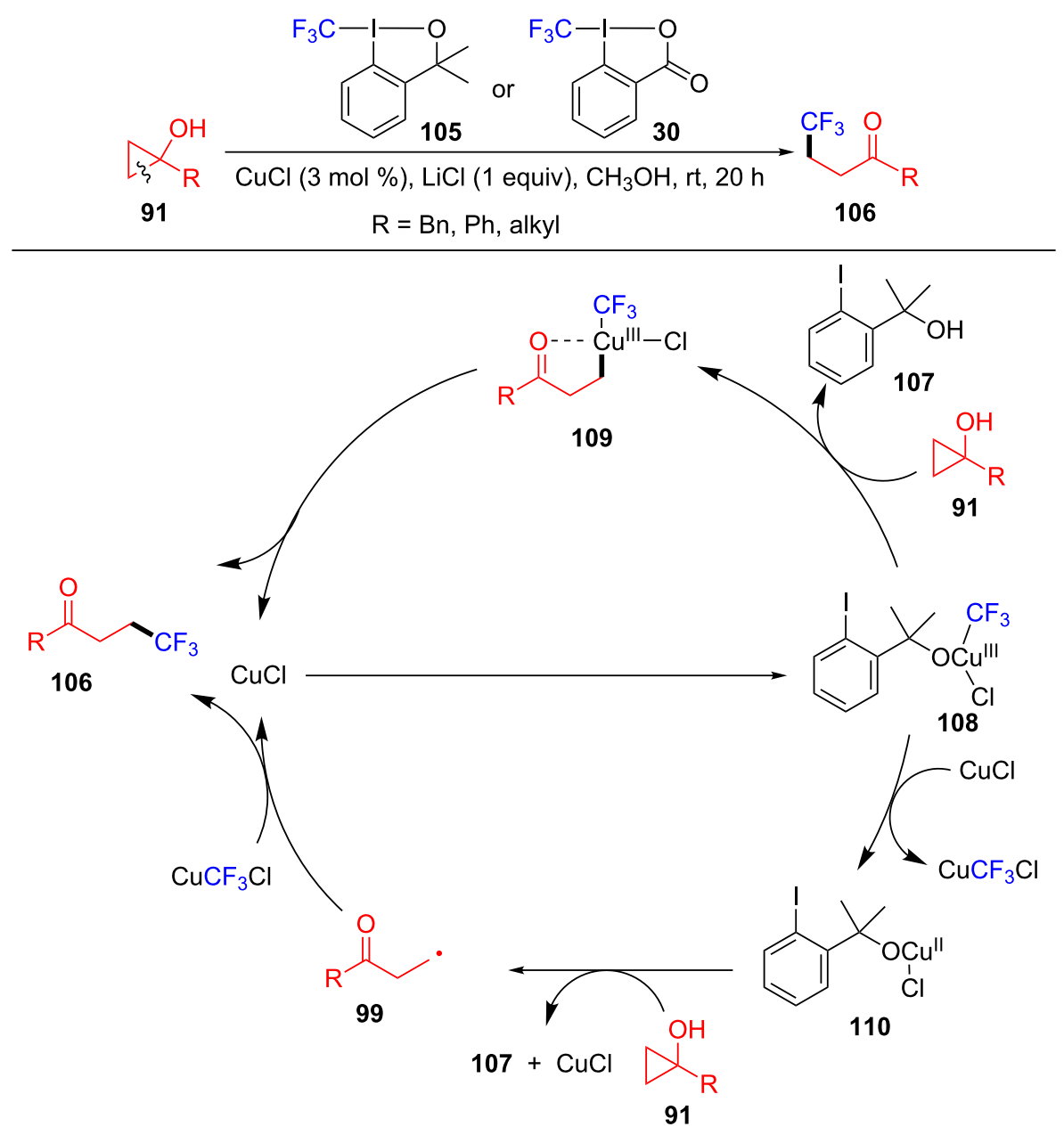

Scheme 23: $\mathrm{Cu}(\mathrm{I})$-catalyzed oxidative ring-opening/trifluoromethylation of cyclopropanols

of copper(III) 108 with cyclopropanol 91. Finally, the desired product $\mathbf{1 0 6}$ is formed through reductive elimination of $\mathrm{CuCl}$ in intermediated 109. On the other hand, the intermediated 108 can lose the $\mathrm{CF}_{3}$ radical to generate the $\mathrm{Cu}(\mathrm{II})$ complex $\mathbf{1 1 0}$. Next, the complex 110 reacts with 91 to give the radical $\mathbf{9 9}$. The desired product 106 was produced by the interception of the $\mathrm{CF}_{3}$ radical, which came from $\mathrm{CuCF}_{3} \mathrm{Cl}$.

In the same year, Dai's group also reported a copper-catalyzed ring-opening and trifluoromethylation or trifluoromethylthiolation of cyclopropanols 91 for the synthesis of $\beta-\mathrm{CF}_{3} / \mathrm{SCF}_{3}$ substituted ketones 113 (Scheme 24) [102]. This strategy was also applied to the synthesis of LY2409021. The LY2409021 was a glucagon receptor antagonist and used in clinical trials for type 2 diabetes mellitus. Xu et al. also presented the similar ring-opening/trifluoromethylation of cyclopropanols for the synthesis of various $\beta$-trifluoromethyl ketones [103].
In this year, Loh et al. [104] and Zhu et al. [105] proposed a oxidative ring-opening and fluorination of cyclopropanols 91 with Selectfluor to construct $\beta$-fluorinated ketones 114 (Scheme 25). In Loh's work, the Fe(III)- or Ag(I)-catalyzed oxidative ringopening and fluorination of cyclopropanols 91 via radical rearrangement is disclosed. Notably, this reaction proceeds at room temperature and tolerates a diverse array of cyclopropanols. In Zhu's work, the fluorination of $\mathbf{9 1}$ a was notable because the seven-membered cyclic product 114a and five-membered cyclic product $114 \mathrm{~b}$ were formed.

Lectka's group also presented a new approach to $\beta$-fluorinated ketones 114 via photocatalyzed ring-opening and fluorination of cyclopropanols 91 with Selectfluor under mild and simple conditions (Scheme 26) [106]. It is worth mentioning that a number of electronically and sterically diverse $\beta$-fluorinated carbonyl-containing compounds 114 and $\gamma$-fluoro alcohols 115 could be prepared through this method. 


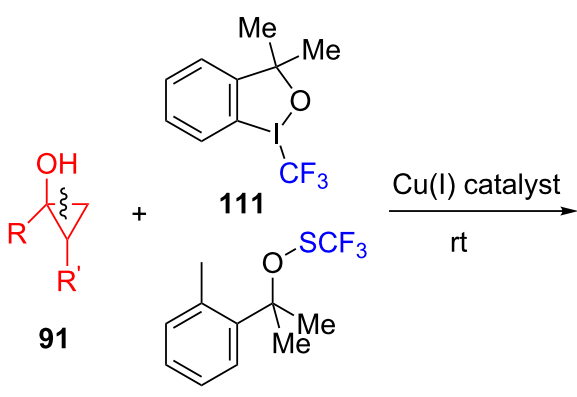

112

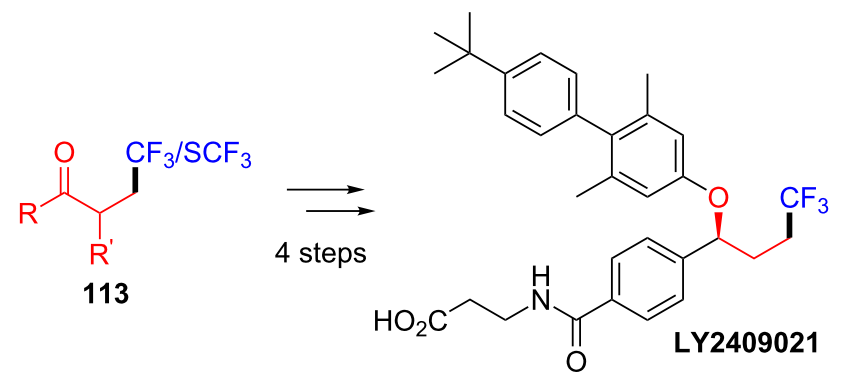

LY2409021

$$
R=A r, \text { alkyl, vinyl } \quad R^{\prime}=H, E t, B n
$$

Scheme 24: $\mathrm{Cu}(\mathrm{I})$-catalyzed oxidative ring-opening and trifluoromethylation/trifluoromethylthiolation of cyclopropanols.

$$
\begin{aligned}
& \underset{\mathrm{R}^{2}}{\stackrel{\mathrm{Selectfluor}(2 \text { equiv })}{\mathrm{AgNO}_{3}\left(\mathrm{H}_{2} \mathrm{O}(1: 1)\right.}} \\
& 91 \quad 114 \\
& \mathrm{R}^{1}=\mathrm{Ar} \text {, naphthyl, } \mathrm{Bn}, \mathrm{PhCH}_{2} \mathrm{CH}_{2}, \mathrm{ClCH}_{2} \mathrm{CH}_{2},(\mathrm{EtO})_{2} \mathrm{CH} \\
& \mathrm{R}^{2}=\mathrm{Et}, \mathrm{Bn}, \mathrm{Me}, \mathrm{Ph} \\
& \mathrm{R}^{3}=\mathrm{H}, \mathrm{Me}
\end{aligned}
$$<smiles>OC1(O)CC2CCc3ccccc3C21O</smiles>

91a<smiles>O=C1CC(F)Cc2ccccc21</smiles>

$114 a$<smiles>O=C1c2ccccc2CCC1CF</smiles>

$114 b$

$(72 \%, a / b=1.5,8 h)$

Scheme 25: $\mathrm{Ag}(\mathrm{I})$-mediated oxidative ring-opening/fluorination of cyclopropanols with Selectfluor.

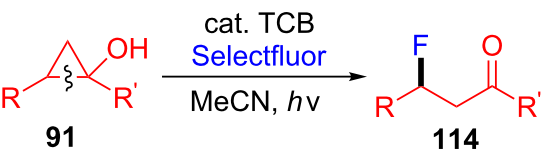

$\mathrm{R}=$ alkyl, $\mathrm{Ph}$

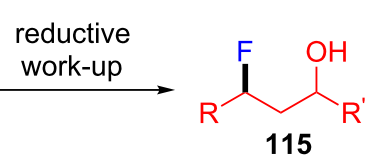

$\mathrm{R}^{\prime}=\mathrm{H}, \mathrm{Me}$

Scheme 26: Photocatalyzed ring-opening/fluorination of cyclopropanols with Selectfluor.

In 2015, Duan and co-workers introduced the $\mathrm{Na}_{2} \mathrm{~S}_{2} \mathrm{O}_{8}-$ promoted ring-opening/alkynylation of cyclopropanols 91 with ethynylbenziodoxolones (EBX) $\mathbf{1 1 6}$ for the synthesis of the alkynylated ketones 117 (Scheme 27) [107]. This reaction involved a $\mathrm{C}-\mathrm{C}$ bond cleavage, radical rearrangement, and $\mathrm{C}-\mathrm{C}$ bond formation, and showed a wide substrates scope under mild conditions. Surprisingly, four- and five-membered cycloalkanols were suitable in this system.

In 2015, Zhu's group developed the silver-catalyzed ringopening of cycloalkanols 91 with NCS 118 for the synthesis of distally chlorinated ketones 119 (Scheme 28) [108]. The reaction was carried out with inexpensive reagents and can also be applied to the distal bromination of cycloalkanols. The possible mechanism is outlined in Scheme 28. The cycloalkoxy radical 98 is generated from cyclopropanol 91 under the action of the metastable $\mathrm{Ag}$ (II) species, which is formed by the interaction of $\mathrm{AgNO}_{3}$ and $\mathrm{K}_{2} \mathrm{~S}_{2} \mathrm{O}_{8}$. The radical 98 undergoes a ring-opening to give the alkyl radical 99. Finally, the radical 99 is intercepted by NCS 118 to furnish the chlorinated ketone 119. The generated imidyl radical 120 can also participate in hydrogen abstraction of cyclopropanol 91 to form the radical $\mathbf{9 8}$. 


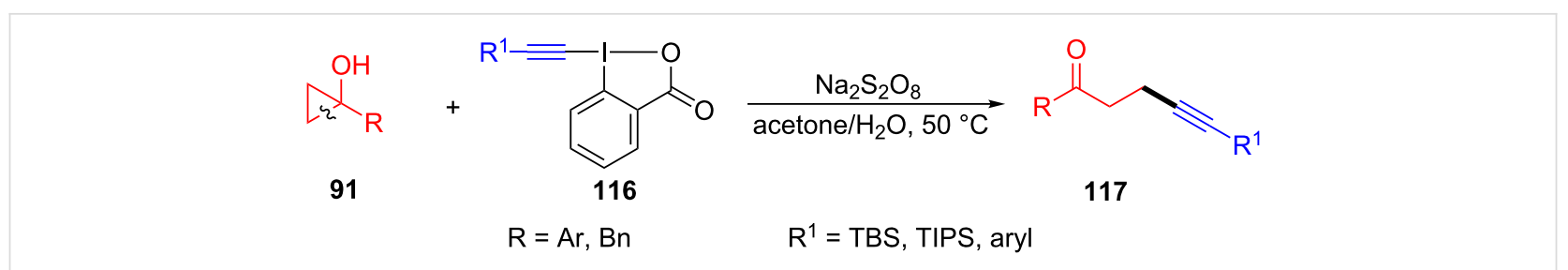

Scheme 27: $\mathrm{Na}_{2} \mathrm{~S}_{2} \mathrm{O}_{8}$-promoted ring-opening/alkynylation of cyclopropanols with EBX.

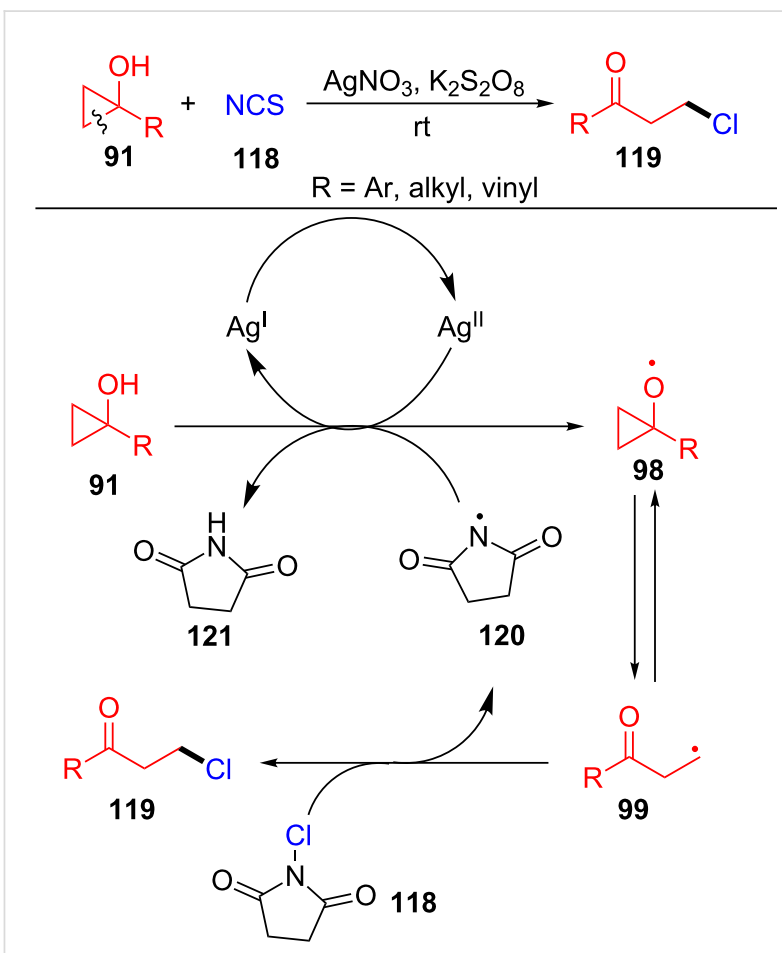

Scheme 28: $\mathrm{Ag}(\mathrm{I})$-catalyzed ring-opening and chlorination of cyclopropanols with aldehydes.

In 2016, the silver-promoted oxidative ring-opening/alkynylation of cyclopropanols 91 with ethynylbenziodoxolones (EBX) 116 had been presented by Li and co-workers (Scheme 29) [109]. Both silver(I) nitrate and potassium persulfate played an important role in this transformation.

In 2016, $\mathrm{Hu}$ and co-workers developed a novel ring-opening of cyclopropanols 91 with acrylamides 122 for the synthesis of oxindoles 123 (Scheme 30) [110]. A series of desired $\gamma$-carbonylalkyl-substituted oxindoles 123 were synthesized between $N$-phenyl acrylamides $\mathbf{1 2 2}$ and tertiary cyclopropanols $\mathbf{9 1}$ through $\mathrm{Na}_{2} \mathrm{~S}_{2} \mathrm{O}_{8}$-promoted radical cyclization under transitionmetal free conditions. With the addition of a radical scavenger such as TEMPO or BHT, the reaction was suppressed remarkably.

In the same year, Dai's group also reported the ring-openinginitiated tandem cyclization of cyclopropanols 91 with acrylamides $\mathbf{1 2 2}$ or 2-isocyanobiphenyls 124 (Scheme 31) [111]. This transformation involved a $\mathrm{C}-\mathrm{C}$ bond cleavage and two $\mathrm{C}-\mathrm{C}$ bond formations, and showed excellent functional group tolerance, satisfactory yields and operational simplicity.

In 2017, Mohr's group proposed a straightforward approach to synthesize $\beta$-fluorinated ketones $\mathbf{1 1 4}$ by using $\mathrm{AgF}_{2}$ as both oxidant and fluorine atom source via the silver(II)-mediated ring-opening and fluorination of cyclopropanols 91 (Scheme 32) [112]. Through this method, a fluorine atom could easily be introduced in the $\beta$-position of a ketone. The mechanism is outlined in Scheme 32, the Ag-alkoxide complex 126 is initially formed from the process of ligand exchange between the substrate and $\mathrm{AgF}_{2}$. The alkoxy radical $\mathbf{9 8}$ is produced via a single-electron oxidation by $\mathrm{Ag}-\mathrm{O}$ bond homolysis. As a feature of the cyclopropane system, the radical 98 goes through a ring fission to form the alkyl radical 99. Finally, the radical 99 abstracted an F-atom from another molecule of $\mathrm{AgF}_{2}$ to produce the target product 114 .

Kananovich and co-workers demonstrated the copper-catalyzed ring-opening and trifluoromethylation of teriary cyclopropanols $\mathbf{9 1}$ with fluorinated sulfinate salts $\mathbf{1 2 7}$ for the synthesis of $\beta$-tri-

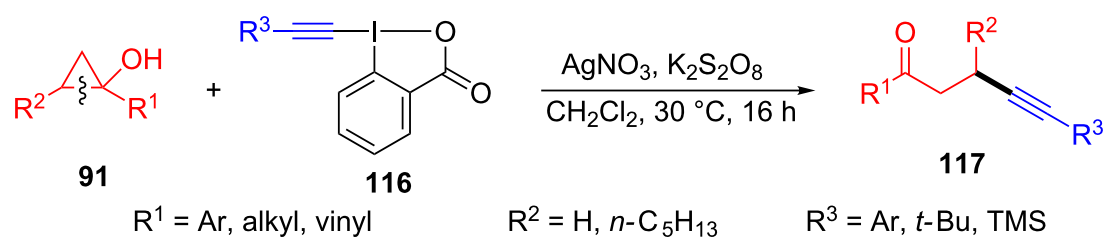

Scheme 29: $\mathrm{Ag}(\mathrm{I})$-catalyzed ring-opening/alkynylation of cyclopropanols with EBX. 


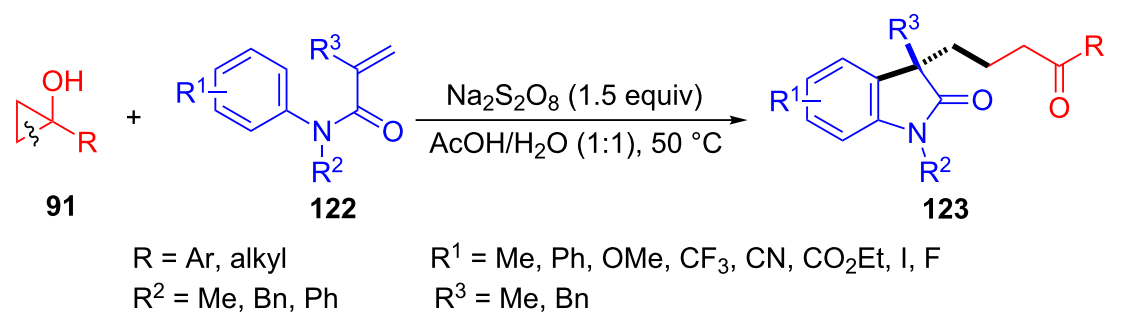<smiles>[R16]N1C(=O)C([R12])(CCCC([2H])=O)c2cc[R3]([H])cc21</smiles>

$\mathrm{R}^{1}=\mathrm{Me}$

$\mathrm{R}^{2}=\mathrm{Me}, \mathrm{Bn}$,

$\mathrm{R}^{3}=\mathrm{H}, \mathrm{Me}, \mathrm{OMe}, \mathrm{Cl}, \mathrm{CF}_{3}$

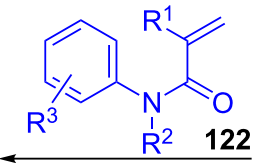

少; 99

$99 \longrightarrow 124$<smiles>[R]C(=O)CCc1nc2ccc[R10]c2c2ccc[R1](C)c12</smiles>

125

$\mathrm{R}^{4}$ and/or $\mathrm{R}^{5}=\mathrm{H}, \mathrm{Me}, t-\mathrm{Bu}, \mathrm{CF}_{3}$

Scheme 31: Cyclopropanol ring-opening initiated tandem cyclization with acrylamides or 2-isocyanobiphenyls.

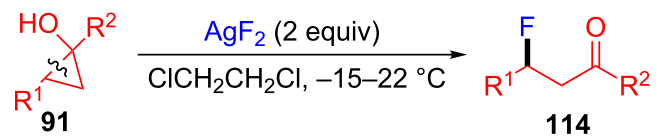

$\mathrm{R}^{1}=\mathrm{Ph}, p-\mathrm{MeC}_{6} \mathrm{H}_{4}, p-t-\mathrm{BuC}_{6} \mathrm{H}_{4}, \mathrm{Bn}, p-\mathrm{EtBn}$ $\mathrm{R}^{2}=\mathrm{Me}, \mathrm{iPr}, t-\mathrm{Bu}, \mathrm{Ph}, \mathrm{Bn}$

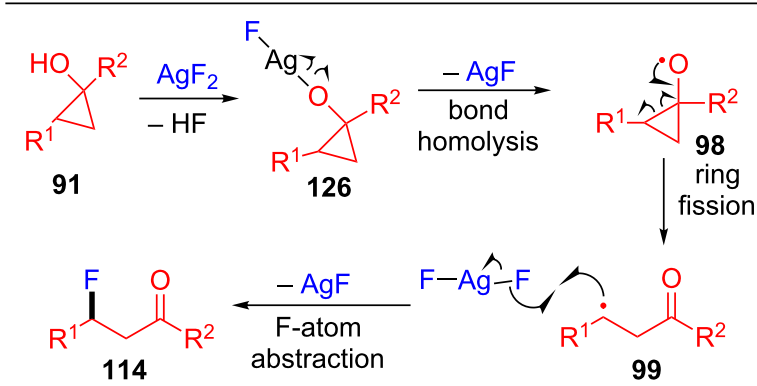

Scheme 32: $\mathrm{Ag}(\mathrm{II})$-mediated oxidative ring-opening/fluorination of cyclopropanols with $\mathrm{AgF}_{2}$

fluoromethyl ketones $\mathbf{1 2 8}$ at room temperature and in an open flask (Scheme 33) [113]. The presented results provided an efficient and convenient method for the synthesis of diverse fulorinated ketones from cyclopropanols.

In the same year, this group developed a similar copper-catalyzed ring-opening and sulfonylation of teriary cyclopropanols
91 with sodium sulfinates $\mathbf{1 2 9}$ for the synthesis of $\gamma$-keto sulfones 130 in excellent yields (Scheme 34) [114]. The reaction was compatible with a series of fluoroalkyl, aryl and alkyl sulfinate salts. Notably, oxygen instead of THBP as oxidation was viable in this transformation.

In 2017, Reddy and co-workers reported the first radical cyclization of propiolamides (131 and 133) with cyclopropanols 91 for the synthesis of azaspiro[4.5]deca-3,6,9-triene-2,8-diones 132 and 6,7-dihydro-3 $H$-pyrrolo[2,1-j]quinoline-3,9 $(5 H)$-diones 134 (Scheme 35) [115]. Interestingly, this transformation proceeded under transition-metal-free conditions with high selectivity and yields. A series of substituents such as methoxy, dimethoxy, trimethoxy, methyl, chloro, bromo, and fluoro on the aromatic ring of cyclopropanols were tolerated well. The mechanism is outlined in Scheme 35. A $\beta$-carbonylalkyl radical 99 is produced from cyclopropanol 91 through a SET process. Then, addition of the radical 99 at the $\alpha$-position of carbonyl in the substrate 131 furnishes the vinyl radical 135. Next, the vinyl radical 135 occurred 5-exo cyclization with the phenyl ring to generate the intermediate 136. Finally, the intermediate 136 underwent oxidation and deprotonation to give the desired product 132.

In this year, Melchiorre's group reported the ring-opening and $[3+2]$-annulation of cyclopropanols 91 with $\alpha, \beta$-unsaturated 


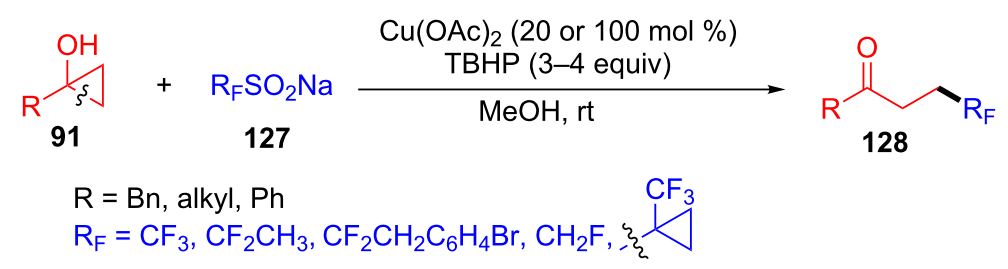

Scheme 33: $\mathrm{Cu}(\mathrm{II})$-catalyzed ring-opening/fluoromethylation of cyclopropanols with sulfinate salts.

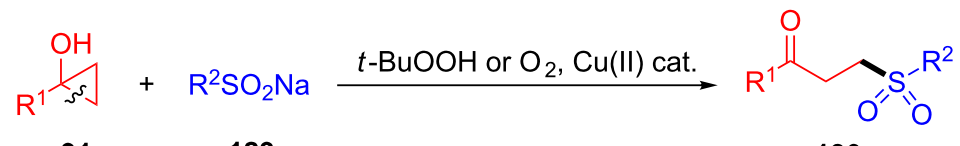

91

129

130

$\mathrm{R}^{1}=$ alkyl, $\mathrm{Ar}$

$R^{2}=$ fluoroalkyl, aryl, alkyl

Scheme 34: $\mathrm{Cu}(\mathrm{II})$-catalyzed ring-opening/sulfonylation of cyclopropanols with sulfinate salts.<smiles>[R]C(=O)CCC1=C(c2ccccc2)C([R])(c2ccccc2)C(=O)N1C</smiles><smiles>COc1ccc(N(CC(=O)N[S+]([O-])([O-])[O-])C(=O)C#Cc2ccccc2)cc1</smiles><smiles>COc1ccc2c(c1)CCCN2C(=O)C#Cc1ccccc1</smiles>

91

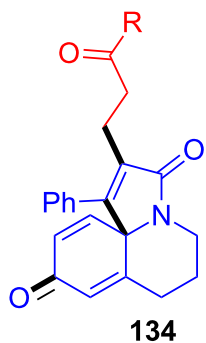

$\mathrm{R}=\mathrm{Ar}$

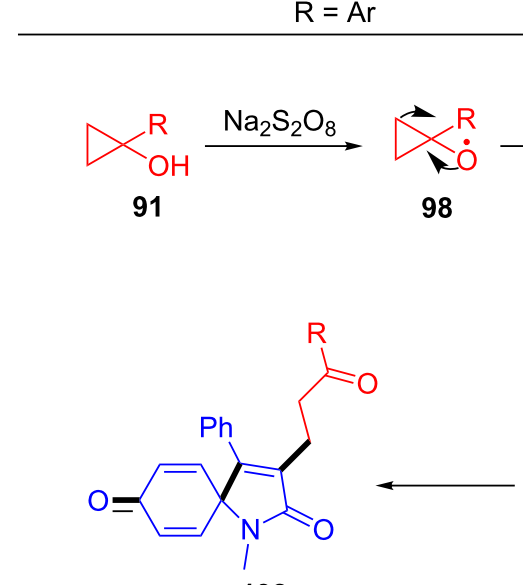

132<smiles>[R]C(=O)CCC1=C(c2ccccc2)C2(C=CC(=O)C=C2)N(C)C1=O</smiles>

137<smiles>[R]C(=O)CCc1c(-c2ccc(OC)cc2)c(=O)n(C)c2ccccc12</smiles>

135<smiles>[R]C(=O)CCC1=C(c2ccccc2)C2(C=CC(OC)C=C2)N(C)C1=O</smiles>

Scheme 35: $\mathrm{Na}_{2} \mathrm{~S}_{2} \mathrm{O}_{8}$-promoted ring-opening/arylation of cyclopropanols with propiolamides.

aldehydes $\mathbf{1 3 8}$ for the synthesis of stereochemically dense cyclopentanols 139 with excellent enantioselectivity (Scheme 36) [116]. This transformation merged a stereocontrolled radical pattern with a classical ionic process in a cascade sequence.

In 2018, Orellana et al. developed the Ag(II)-catalyzed ringopening and functionalization of cyclopropanols 91 with elec- tron-poor aromatic nitrogen heterocyles 140 under acid-free conditions and used a well-defined catalyst $\left[\mathrm{Ag}(\mathrm{II})(\text { bipy })_{2} \mathrm{~S}_{2} \mathrm{O}_{8}\right]$ at low loadings (Scheme 37) [117]. This finding indicated that the silver pyridine complex plays an important role in single electron oxidants of cyclopropanols.

In the same year, a silver-catalyzed ring-opening and difluoromethylthiolation of cyclopropanols 91 with $\mathrm{PhSO}_{2} \mathrm{SCF}_{2} \mathrm{H}$ 

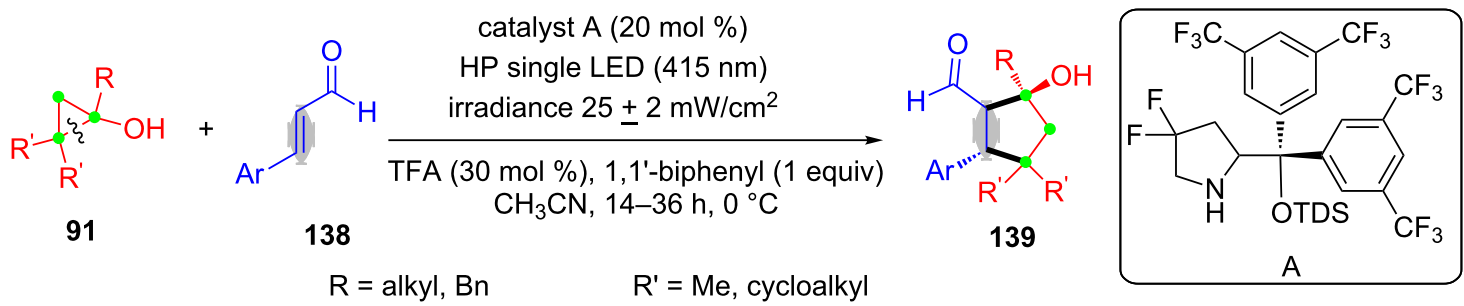

Scheme 36: The ring-opening and [3 +2$]$-annulation of cyclopropanols with $\alpha, \beta$-unsaturated aldehydes.

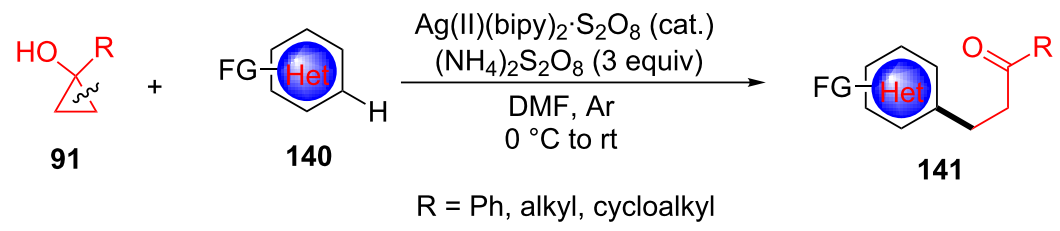

Scheme 37: $\mathrm{Cu}(\mathrm{II})$-catalyzed ring-opening/arylation of cyclopropanols with aromatic nitrogen heterocyles.

142 for the synthesis of difluoromethylthioethers 143 was reported by Shen and co-workers (Scheme 38) [118]. $\mathrm{AgNO}_{3}$ was utilized as catalyst, $\mathrm{K}_{2} \mathrm{~S}_{2} \mathrm{O}_{8}$ as oxidant, and SDS (sodium dodecyl sulfate) as addictive in water. The SDS plays a key role in this transformation, and it enhances the solubility of both reactants in water. The cycloalkanol derivatives with electronrich substituents on the phenyl rings deliver the corresponding products in higher yields than that with electron-deficient substituents.

In 2018, Zhu and co-workers also reported the first silver-catalyzed ring-opening and acylation of cyclopropanols 91 with aldehydes 48 for the synthesis of 1,4-diketones 144 (Scheme 39) [119]. They proposed that the involvement of an uncommon water-assisted 1,2-HAT process was strongly exo- thermic and it promoted the addition of alkyl radicals to $\mathrm{C}=\mathrm{O}$ bonds in aldehydes. The electronic effect of the phenyl rings in the aldehydes showed important influence on the reaction yields.

In 2017, Kananovich developed a simple and efficient one-pot method for the preparation of enantiomerically enriched 2-oxyranyl ketones $\mathbf{1 4 6}$ by aerobic oxidation of easily available cyclopropanols 91 via intermediate formation of peroxyketone intermediates $\mathbf{1 4 5}$, followed by enantioselective epoxide formation in the presence of a poly-L-leucine catalyst and DBU (Scheme 40) [120].

In 2014, a practical method for the conversion of 1,2-disubstituted cyclopropanols 91 derived from Kulinkovich cyclo-

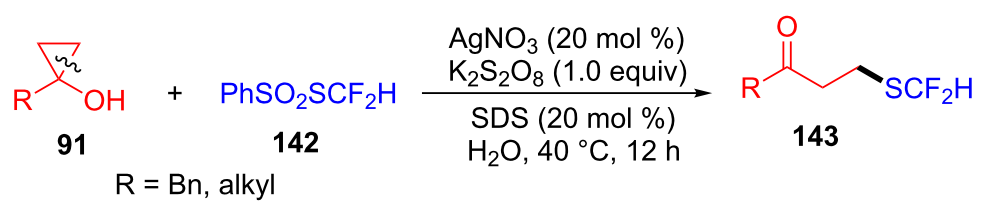

Scheme 38: $\mathrm{Ag}(\mathrm{I})$-catalyzed ring-opening and difluoromethylthiolation of cyclopropanols with $\mathrm{PhSO}_{2} \mathrm{SCF}_{2} \mathrm{H}$.

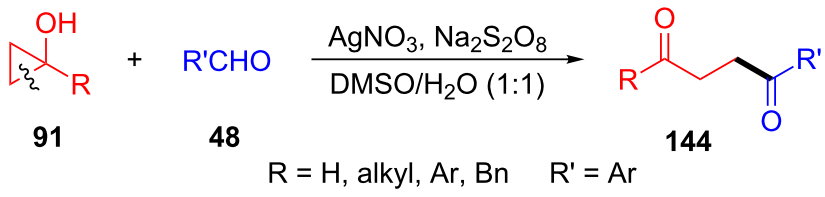




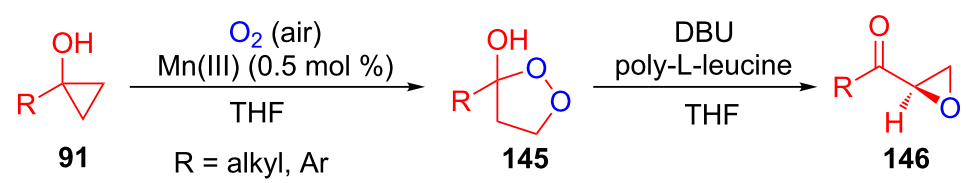

Scheme 40: Aerobic oxidation ring-opening of cyclopropanols for the synthesis of 2-oxyranyl ketones.

propanation into linear enones $\mathbf{1 4 7}$ was developed by $\mathrm{Wu}$ and co-workers [121]. The approach features the regioselective cleavage of the cyclopropane rings in $\mathrm{EtOH}$ at room temperature with cheap and readily available $\mathrm{Co}(\mathrm{acac})_{2}$ as the catalyst and air as the reagent (Scheme 41).

In 2015, Tyagi's group presented a biomimetic synthesis of metabolite 149 from intermediate 148 by using catalytic vanadyl acetylacetonate and molecular $\mathrm{O}_{2}$ (Scheme 42) [122]. The transformation went through aerobic oxidation ringopening of cyclopropanols. The results showed that the oxygen atom of newly-formed hydroxy group came from molecular $\mathrm{O}_{2}$.

\section{Conclusion}

In the past 20 years, the field of oxidative radical ring-opening/ cyclization of cyclopropane derivatives (including methylenecyclopropanes, cyclopropyl olefins and cyclopropanols) has experienced significant advances. This utility has been highlighted in a number of complex natural product syntheses. In this review, we have systematically summarized various oxidative radical strategies developed for the ring-opening and cyclization of cyclopropane derivatives. Despite these advances, there still exist opportunities for exploration and many questions to be addressed. Although oxidative radical ring-opening/ cyclization of functionalized cyclopropane derivatives has been well developed, the ring-opening/cyclization of common cyclopropane derivatives is conspicuously absent. On the other hand, green and environmentally friendly strategies, such as photocatalysis or electrocatalysis, can be another orientation for further developments. This review opens the scope for future developments in new methodologies which promise the synthesis of novel fused cyclic systems with a wide range of medicinal and

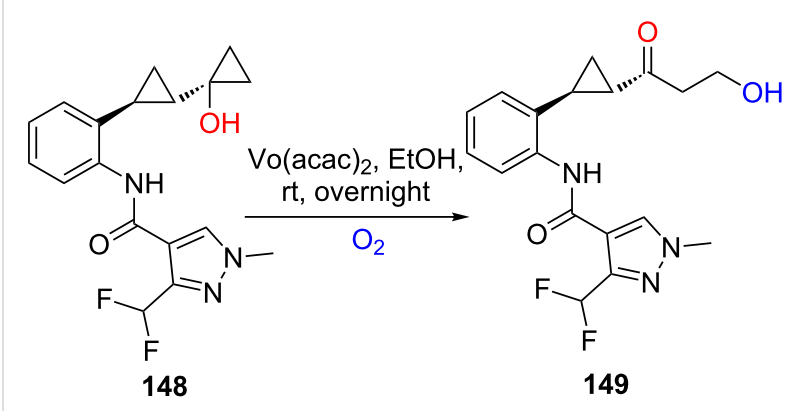

Scheme 42: Aerobic oxidation ring-opening of cyclopropanols for the synthesis of metabolite.

synthetic applications.

\section{Acknowledgements}

The work was supported by the National Nature Science Foundation of China (Grant No. 21602056), Scientific Research Fund of Hunan Provincial Science and Technology Department (Grant No. 2018JJ3208), Scientific Research Fund of Hunan Provincial Education Department (Grant No. 16A087).

\section{ORCID ${ }^{\circledR}$ iDs}

Yu Liu - https://orcid.org/0000-0003-4555-8238

\section{References}

1. Brandi, A.; Goti, A. Chem. Rev. 1998, 98, 589-636. doi:10.1021/cr940341t

2. Schneider, T. F.; Kaschel, J.; Werz, D. B. Angew. Chem., Int. Ed. 2014, 53, 5504-5523. doi:10.1002/anie.201309886

3. Rubin, M.; Rubina, M.; Gevorgyan, V. Chem. Rev. 2007, 107, 3117-3179. doi:10.1021/cr050988I

4. de Meijere, A. Angew. Chem., Int. Ed. Engl. 1979, 18, 809-826. doi:10.1002/anie.197908093

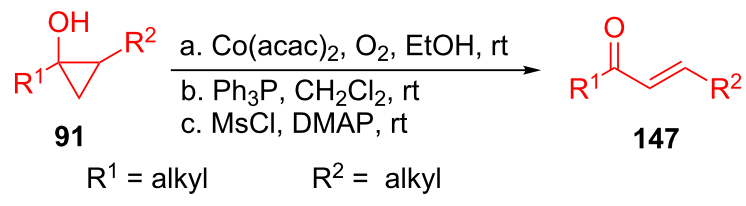


5. Wu, W.; Lin, Z.; Jiang, H. Org. Biomol. Chem. 2018, 16, 7315-7329. doi:10.1039/c8ob01187g

6. Agrawal, D.; Yadav, V. K. Chem. Commun. 2008, 6471-6488. doi:10.1039/b812285g

7. Carson, C. A.; Kerr, M. A. Chem. Soc. Rev. 2009, 38, 3051-3060. doi:10.1039/b901245c

8. Cavitt, M. A.; Phun, L. H.; France, S. Chem. Soc. Rev. 2014, 43, 804-818. doi:10.1039/c3cs60238a

9. Chen, D. Y. K.; Pouwerb, R. H.; Richardc, J. A. Chem. Soc. Rev. 2012, 41, 4631-4642. doi:10.1039/c2cs35067j

10. Gnad, F.; Reiser, O. Chem. Rev. 2003, 103, 1603-1624. doi:10.1021/cr010015v

11. Maas, G. Chem. Soc. Rev. 2004, 33, 183-190. doi:10.1039/b309046a

12. Qian, D.; Zhang, J. Chem. Soc. Rev. 2015, 44, 677-698. doi: $10.1039 / \mathrm{c} 4 \mathrm{cs} 00304 \mathrm{~g}$

13. Rademacher, P. Chem. Rev. 2003, 103, 933-976. doi:10.1021/cr0100143

14. Walsh, R. Chem. Soc. Rev. 2005, 34, 714-732. doi:10.1039/b310975p

15. Wessjohann, L. A.; Brandt, W.; Thiemann, T. Chem. Rev. 2003, 103, 1625-1648. doi:10.1021/cr0100188

16. Fumagalli, G.; Stanton, S.; Bower, J. F. Chem. Rev. 2017, 117, 9404-9432. doi:10.1021/acs.chemrev.6b00599

17. Shi, M.; Shao, L.-X.; Lu, J.-M.; Wei, Y.; Mizuno, K.; Maeda, H. Chem. Rev. 2010, 110, 5883-5913. doi:10.1021/cr900381k

18. Yu, L.-Z.; Chen, K.; Zhu, Z.-Z.; Shi, M. Chem. Commun. 2017, 53, 5935-5945. doi:10.1039/c7cc02596c

19. Wong, H. N. C.; Hon, M. Y.; Tse, C. W.; Yip, Y. C.; Tanko, J.; Hudlicky, T. Chem. Rev. 1989, 89, 165-198. doi:10.1021/cr00091a005

20. Pellissier, H. Tetrahedron 2010, 66, 8341-8375. doi:10.1016/j.tet.2010.08.031

21. Goldschmidt, Z.; Crammer, B. Chem. Soc. Rev. 1988, 17, 229-267. doi:10.1039/cs9881700229

22. Meazza, M.; Guo, H.; Rios, R. Org. Biomol. Chem. 2017, 15, 2479-2490. doi:10.1039/c6ob02647h

23. Gibson, D. H.; DePuy, C. H. Chem. Rev. 1974, 74, 605-623. doi:10.1021/cr60292a001

24. Kulinkovich, O. G. Chem. Rev. 2003, 103, 2597-2632. doi: $10.1021 / \mathrm{cr} 010012 \mathrm{i}$

25. Wu, X.; Zhu, C. Chem. Rec. 2018, 18, 587-598. doi:10.1002/tcr.201700090

26. Nikolaev, A.; Orellana, A. Synthesis 2016, 1741-1768. doi:10.1055/s-0035-1560442

27. Brandi, A.; Cicchi, S.; Cordero, F. M.; Goti, A. Chem. Rev. 2014, 114, 7317-7420. doi:10.1021/cr400686j

28. Grover, H. K.; Emmett, M. R.; Kerr, M. A. Org. Biomol. Chem. 2015, 13, 655-671. doi:10.1039/c4ob02117g

29. Nonhebel, D. C. Chem. Soc. Rev. 1993, 22, 347-359. doi:10.1039/cs9932200347

30. Reissig, H.-U.; Zimmer, R. Chem. Rev. 2003, 103, 1151-1196. doi:10.1021/cr010016n

31. Thankachan, A. P.; Sindhu, K. S.; Krishnan, K. K.; Anilkumar, G. Org. Biomol. Chem. 2015, 13, 8780-8802. doi:10.1039/c5ob01088h

32. McCarroll, A. J.; Walton, J. C. J. Chem. Soc., Perkin Trans. 12001 , 3215-3229. doi:10.1039/b105234a

33. Dowd, P.; Zhang, W. Chem. Rev. 1993, 93, 2091-2115. doi:10.1021/cr00022a007

34. Easton, C. J. Chem. Rev. 1997, 97, 53-82. doi:10.1021/cr9402844
35. Frey, P. A.; Hegeman, A. D.; Reed, G. H. Chem. Rev. 2006, 106, 3302-3316. doi:10.1021/cr050292s

36. Snider, B. B. Chem. Rev. 1996, 96, 339-364. doi:10.1021/cr950026m

37. Studer, A. Chem. Soc. Rev. 2004, 33, 267-273. doi:10.1039/b307652k

38. Penkett, C. S.; Sanderson, J. T. Annu. Rep. Prog. Chem., Sect. B: Org. Chem. 2001, 97, 3-20. doi:10.1039/b102954c

39. Recupero, F.; Punta, C. Chem. Rev. 2007, 107, 3800-3842. doi:10.1021/cr040170k

40. Rowlands, G. J. Annu. Rep. Prog. Chem., Sect. B: Org. Chem. 2012, 108, 15-28. doi:10.1039/c2oc90010f

41. Shang, X.; Liu, Z.-Q. Org. Biomol. Chem. 2016, 14, 7829-7831. doi:10.1039/c6ob00797j

42. Litwinienko, G.; Beckwith, A. L. J.; Ingold, K. U. Chem. Soc. Rev. 2011, 40, 2157-2163. doi:10.1039/c1cs15007c

43. Zhou, H.; Huang, X.; Chen, W. J. Org. Chem. 2004, 69, 5471-5472. doi:10.1021/jo0496289

44. Snider, B. B.; Patricia, J. J.; Kates, S. A. J. Org. Chem. 1988, 53, 2137-2143. doi:10.1021/jo00245a001

45. Heiba, E.-A. I.; Dessau, R. M. J. Org. Chem. 1974, 39, 3456-3457. doi:10.1021/jo00937a052

46. Heiba, E. I.; Dessau, R. M.; Koehl, W. J., Jr. J. Am. Chem. Soc. 1968, 90, 5905-5906. doi:10.1021/ja01023a049

47. Back, T. G.; Muralidharan, K. R. J. Org. Chem. 1989, 54, 121-125. doi:10.1021/jo00262a028

48. Citterio, A.; Fancelli, D.; Finzi, C.; Pesce, L.; Santi, R. J. Org. Chem. 1989, 54, 2713-2718. doi:10.1021/jo00272a047

49. Huang, J.-W.; Shi, M. J. Org. Chem. 2005, 70, 3859-3863. doi:10.1021/jo050181t

50. Yu, L.; Wu, Y.; Chen, T.; Pan, Y.; Xu, Q. Org. Lett. 2013, 15, 144-147. doi:10.1021/ol3031846

51. Yu, L.; Huang, X. Synlett 2007, 1371-1374. doi:10.1055/s-2007-980361

52. Xu, B.; Chen, Y.; Shi, M. Tetrahedron Lett. 2002, 43, 2781-2784. doi:10.1016/s0040-4039(02)00384-2

53. Liu, L.-P.; Shi, M. Chem. Commun. 2004, 2878-2879. doi:10.1039/b412823k

54. Kochi, J. K. J. Am. Chem. Soc. 1963, 85, 1958-1968. doi:10.1021/ja00896a014

55. Kochi, J. K.; Bemis, A. J. Am. Chem. Soc. 1968, 90, 4038-4051. doi:10.1021/ja01017a022

56. Kochi, J. K. Free Radicals; Wiley: New York, NY, U.S.A., 1968; Vol. I, p 591.

57. Yu, L.; Huang, X.; Xie, M. H. Synlett 2006, 423-426. doi:10.1055/s-2006-926268

58. Huang, X.; Yu, L. Synlett 2005, 2953-2957. doi:10.1055/s-2005-918947

59. Miao, M.; Huang, X. J. Org. Chem. 2009, 74, 5636-5639. doi:10.1021/jo900805a

60. Ma, S.; Lu, L.; Zhang, J. J. Am. Chem. Soc. 2004, 126, 9645-9660. doi:10.1021/ja0494860

61. Liu, Z.-Q.; Sun, L.; Wang, J.-G.; Han, J.; Zhao, Y.-K.; Zhou, B Org. Lett. 2009, 11, 1437-1439. doi:10.1021/ol900145u

62. Zhu, Z.-Z.; Chen, K.; Yu, L.-Z.; Tang, X.-Y.; Shi, M. Org. Lett. 2015, 17, 5994-5997. doi:10.1021/acs.orglett.5b02940

63. Wang, X.; Ye, Y.; Zhang, S.; Feng, J.; Xu, Y.; Zhang, Y.; Wang, J. J. Am. Chem. Soc. 2011, 133, 16410-16413. doi:10.1021/ja207775a

64. Dong, X.; Sang, R.; Wang, Q.; Tang, X.-Y.; Shi, M. Chem. - Eur. J. 2013, 19, 16910-16915. doi:10.1002/chem.201303623 
65. Li, Y.; Lu, Y.; Qiu, G.; Ding, Q. Org. Lett. 2014, 16, 4240-4243. doi:10.1021/ol501939m

66. Xu, J.; Wang, Y.-L.; Gong, T.-J.; Xiao, B.; Fu, Y. Chem. Commun. 2014, 50, 12915-12918. doi:10.1039/c4cc05692b

67. Chen, M.-T.; Tang, X.-Y.; Shi, M. Org. Chem. Front. 2017, 4, 86-90. doi:10.1039/c6qo00536e

68. Liu, Y.; Wang, Q.-L.; Zhou, C.-S.; Xiong, B.-Q.; Zhang, P.-L.; Yang, C.-a.; Tang, K.-W. J. Org. Chem. 2017, 82, 7394-7401. doi:10.1021/acs.joc.7b00970

69. Pan, C.; Zhang, H.; Zhu, C. Tetrahedron Lett. 2016, 57, 595-598. doi:10.1016/j.tetlet.2015.12.092

70. Feng, S.; Xie, X.; Zhang, W.; Liu, L.; Zhong, Z.; Xu, D.; She, X. Org. Lett. 2016, 18, 3846-3849. doi:10.1021/acs.orglett.6b01857

71. Wei, W.-T.; Zhou, M.-B.; Fan, J.-H.; Liu, W.; Song, R.-J.; Liu, Y.; Hu, M.; Xie, P.; Li, J.-H. Angew. Chem., Int. Ed. 2013, 52, 3638-3641. doi:10.1002/anie.201210029

72. Zhang, X.; Wang, M.; Li, P.; Wang, L. Chem. Commun. 2014, 50, 8006-8009. doi:10.1039/c4cc01189a

73. Liu, Y.; Wang, Q.-L.; Zhou, C.-S.; Xiong, B.-Q.; Zhang, P.-L.; Yang, C.-a.; Tang, K.-W. J. Org. Chem. 2018, 83, 4657-4664. doi:10.1021/acs.joc.8b00427

74. Lv, L.; Xi, H.; Bai, X.; Li, Z. Org. Lett. 2015, 17, 4324-4327. doi:10.1021/acs.orglett.5b02138

75. Jia, F.; Liu, K.; Xi, H.; Lu, S.; Li, Z. Tetrahedron Lett. 2013, 54, 6337-6340. doi:10.1016/j.tetlet.2013.09.048

76. Chatgilialoglu, C.; Crich, D.; Komatsu, M.; Ryu, I. Chem. Rev. 1999, 99, 1991-2070. doi:10.1021/cr9601425

77. Pan, C.; Ni, Q.; Fu, Y.; Yu, J.-T. J. Org. Chem. 2017, 82, 7683-7688. doi:10.1021/acs.joc.7b01255

78. Yu, L.-Z.; Xu, Q.; Tang, X.-Y.; Shi, M. ACS Catal. 2016, 6, 526-531. doi:10.1021/acscatal.5b02400

79. Horner, J. H.; Tanaka, N.; Newcomb, M. J. Am. Chem. Soc. 1998, 120, 10379-10390. doi:10.1021/ja9819460

80. Hollis, R.; Hughes, L.; Bowry, V. W.; Ingold, K. U. J. Org. Chem. 1992, 57, 4284-4287. doi:10.1021/jo00041a040

81. Wang, L.-J.; Wang, A.-Q.; Xia, Y.; Wu, X.-X.; Liu, X.-Y.; Liang, Y.-M. Chem. Commun. 2014, 50, 13998-14001. doi:10.1039/c4cc06923d

82. Chen, K.; Zhu, Z.-Z.; Liu, J.-X.; Tang, X.-Y.; Wei, Y.; Shi, M. Chem. Commun. 2016, 52, 350-353. doi:10.1039/c5cc07292a

83. Stokes, B. J.; Richert, K. J.; Driver, T. G. J. Org. Chem. 2009, 74, 6442-6451. doi:10.1021/jo901224k

84. Driver, T. G. Org. Biomol. Chem. 2010, 8, 3831-3846. doi:10.1039/c005219c

85. Sun, K.; Liu, S.; Bec, P. M.; Driver, T. G. Angew. Chem., Int. Ed. 2011, 50, 1702-1706. doi:10.1002/anie.201006917

86. Stokes, B. J.; Liu, S.; Driver, T. G. J. Am. Chem. Soc. 2011, 133, 4702-4705. doi:10.1021/ja111060q

87. Fiori, K. W.; Du Bois, J. J. Am. Chem. Soc. 2007, 129, 562-568. doi:10.1021/ja0650450

88. Zalatan, D. N.; Du Bois, J. J. Am. Chem. Soc. 2009, 131, 7558-7559. doi:10.1021/ja902893u

89. Zhang, X.; Ke, Z.; DeYonker, N. J.; Xu, H.; Li, Z.-F.; Xu, X.; Zhang, X.; Su, C.-Y.; Phillips, D. L.; Zhao, C. J. Org. Chem. 2013, 78, 12460-12468. doi:10.1021/jo402101h

90. Zhang, J.; Jiang, J.; Xu, D.; Luo, Q.; Wang, H.; Chen, J.; Li, H.; Wang, Y.; Wan, X. Angew. Chem., Int. Ed. 2015, 54, 1231-1235. doi:10.1002/anie.201408874

91. Fan, X.; Yu, L.-Z.; Wei, Y.; Shi, M. Org. Lett. 2017, 19, 4476-4479. doi:10.1021/acs.orglett.7b01957
92. Shi, M.; Lu, J.-M.; Xu, G.-C. Tetrahedron Lett. 2005, 46, 4745-4748. doi:10.1016/j.tetlet.2005.05.029

93. Mathew, L.; Warkentin, J. J. Am. Chem. Soc. 1986, 108, 7981-7984. doi:10.1021/ja00285a016

94. Chu, J. Y. C.; Lewicki, J. W. J. Org. Chem. 1977, 42, 2491-2493. doi:10.1021/jo00434a031

95. Kippo, T.; Hamaoka, K.; Ryu, I. J. Am. Chem. Soc. 2013, 135, 632-635. doi:10.1021/ja311821h

96. Xie, H.; Xu, B. Eur. J. Org. Chem. 2016, 2594-2598. doi:10.1002/ejoc.201600380

97. Li, J.; Chen, J.; Jiao, W.; Wang, G.; Li, Y.; Cheng, X.; Li, G. J. Org. Chem. 2016, 81, 9992-10001. doi:10.1021/acs.joc.6b01825

98. Wang, Y.-F.; Toh, K. K.; Ng, E. P. J.; Chiba, S. J. Am. Chem. Soc. 2011, 133, 6411-6421. doi:10.1021/ja200879w

99. Ilangovan, A.; Saravanakumar, S.; Malayappasamy, S. Org. Lett. 2013, 15, 4968-4971. doi:10.1021/ol402229m

100.Lu, S.-C.; Li, H.-S.; Xu, S.; Duan, G.-Y. Org. Biomol. Chem. 2017, 15, 324-327. doi:10.1039/c6ob02330d

101.Kananovich, D. G.; Konik, Y. A.; Zubrytski, D. M.; Järving, I.; Lopp, M. Chem. Commun. 2015, 51, 8349-8352. doi:10.1039/c5cc02386f

102.Li, Y.; Ye, Z.; Bellman, T. M.; Chi, T.; Dai, M. Org. Lett. 2015, 17, 2186-2189. doi:10.1021/acs.orglett.5b00782

103.He, X.-P.; Shu, Y.-J.; Dai, J.-J.; Zhang, W.-M.; Feng, Y.-S.; Xu, H.-J. Org. Biomol. Chem. 2015, 13, 7159-7163. doi:10.1039/c5ob00808e

104.Ren, S.; Feng, C.; Loh, T.-P. Org. Biomol. Chem. 2015, 13, 5105-5109. doi:10.1039/c5ob00632e

105.Zhao, H.; Fan, X.; Yu, J.; Zhu, C. J. Am. Chem. Soc. 2015, 137, 3490-3493. doi:10.1021/jacs.5b00939

106.Bloom, S.; Bume, D. D.; Pitts, C. R.; Lectka, T. Chem. - Eur. J. 2015, 21, 8060-8063. doi:10.1002/chem.201501081

107.Wang, S.; Guo, L.; Wang, H.; Duan, X.-H. Org. Lett. 2015, 17 , 4798-4801. doi:10.1021/acs.orglett.5b02353

108.Fan, X.; Zhao, H.; Yu, J.; Bao, X.; Zhu, C. Org. Chem. Front. 2016, 3, 227-232. doi:10.1039/c5qo00368g

109.Wang, C. Y.; Song, R. J.; Xie, Y. X.; Li, J. H. Synthesis 2016, 223-230. doi:10.1055/s-0035-1560374

110.Guo, L.-N.; Deng, Z.-Q.; Wu, Y.; Hu, J. RSC Adv. 2016, 6, 27000-27003. doi:10.1039/c6ra03431d

111.Davis, D. C.; Haskins, C. W.; Dai, M. G. Synlett 2017, 28, 913-918. doi:10.1055/s-0036-1588929

112.Deng, Y.; Kauser, N. I.; Islam, S. M.; Mohr, J. T. Eur. J. Org. Chem. 2017, 5872-5879. doi:10.1002/ejoc.201700899

113.Konik, Y. A.; Kudrjashova, M.; Konrad, N.; Kaabel, S.; Järving, I.; Lopp, M.; Kananovich, D. G. Org. Biomol. Chem. 2017, 15, 4635-4643. doi:10.1039/c7ob00680b

114.Konik, Y. A.; Elek, G. Z.; Kaabel, S.; Järving, I.; Lopp, M.; Kananovich, D. G. Org. Biomol. Chem. 2017, 15, 8334-8340. doi:10.1039/c7ob01605k

115. Reddy, C. R.; Yarlagadda, S.; Ramesh, B.; Reddy, M. R.; Sridhar, B.; Reddy, B. V. S. Eur. J. Org. Chem. 2017, 2332-2337. doi:10.1002/ejoc.201700058

116. Woźniak, Ł.; Magagnano, G.; Melchiorre, P. Angew. Chem., Int. Ed. 2018, 57, 1068-1072. doi:10.1002/anie.201711397

117. Nikolaev, A.; Legault, C. Y.; Zhang, M.; Orellana, A. Org. Lett. 2018, 20, 796-799. doi:10.1021/acs.orglett.7b03938

118.Xu, B.; Wang, D.; Hu, Y.; Shen, Q. Org. Chem. Front. 2018, 5 , 1462-1465. doi:10.1039/c8qo00115d

119. Che, C.; Qian, Z.; Wu, M.; Zhao, Y.; Zhu, G. J. Org. Chem. 2018, 83, 5665-5673. doi:10.1021/acs.joc.8b00666 
120.Elek, G. Z.; Borovkov, V.; Lopp, M.; Kananovich, D. G. Org. Lett. 2017, 19, 3544-3547. doi:10.1021/acs.orglett.7b01519

121.Han, W.-B.; Li, S.-G.; Lu, X.-W.; Wu, Y. Eur. J. Org. Chem. 2014, 3841-3846. doi:10.1002/ejoc.201402175

122.Tyagi, S.; Cook, C. D.; DiDonato, D. A.; Key, J. A.; McKillican, B. P.; Eberle, W. J.; Carlin, T. J.; Hunt, D. A.; Marshall, S. J.; Bow, N. L. J. Org. Chem. 2015, 80, 11941-11947. doi:10.1021/acs.joc.5b01700

\section{License and Terms}

This is an Open Access article under the terms of the Creative Commons Attribution License

(http://creativecommons.org/licenses/by/4.0). Please note that the reuse, redistribution and reproduction in particular requires that the authors and source are credited.

The license is subject to the Beilstein Journal of Organic Chemistry terms and conditions:

(https://www.beilstein-journals.org/bjoc)

The definitive version of this article is the electronic one which can be found at: doi:10.3762/bjoc. 15.23 